\title{
Distribution of Mycelial Colonies and Lesions in Field-Grown Barley Inoculated with Fusarium graminearum
}

\author{
Sharon M. Lewandowski, W. R. Bushnell, and C. Kent Evans
}

First author: Department of Plant Pathology, 491 Borlaug Hall, University of Minnesota, St. Paul 55108; second author: Cereal Disease Laboratory, Agricultural Research Service, United States Department of Agriculture, 1551 Lindig St., St. Paul, MN 55108; and third author: Biology Department, Utah State University, Logan 84322.

Accepted for publication 22 December 2005.

\begin{abstract}
Lewandowski, S. M., Bushnell, W. R., and Evans, C. K. 2006. Distribution of mycelial colonies and lesions in field-grown barley inoculated with Fusarium graminearum. Phytopathology 96:567-581.

External surfaces of barley florets have thick-walled epidermal cells resistant to direct penetration by the head blight pathogen, Fusarium graminearum. Surfaces within the floral cavity have thin-walled, susceptible cells. How the fungus gains access to the floral cavity, causing head blight, has not been determined. To investigate pathways of entry, field-grown plants were sprayed with macroconidial inoculum after heads emerged from the flag leaf sheath and then were mist irrigated daily in the morning and evening. On selected days, 1 to 8 days after inoculation (DAI), 80 to 190 florets per day were harvested, dissected, and examined for presence and location of mycelial colonies. At 1 to 12 DAI, 57 to 100

crevices were open for entry until $\approx 8$ days after heads emerged. Most florets had mycelial colonies on the external surface in a sheltered pocket near the base of the ventral furrow of the palea. Mycelia spread laterally from the furrow to the crevice between lemma and palea. Anther colonization had only a minor role in invasion of florets. Hyphal penetration of stomates was not seen. Lesions usually developed first within $3 \mathrm{~mm}$ of the floret apex or $3 \mathrm{~mm}$ of the floret base. Within florets, lesions often were contiguous between lemma and palea, palea and caryopsis, or in all three floret parts. However, lesions in the caryopsis developed later and were fewer in number than in the lemma and palea and always were associated with lesions in the palea. The results show the importance of initial mycelial colonization of floret outer surfaces, pathways of entry via lemma or palea crevices or floret mouth, and spread of lesions within the floret at interfaces between lemma, palea, and caryopsis.
\end{abstract} florets likewise were examined for lesions. Patterns of colonization indicated that the fungus entered florets principally through crevices between the overlapping lemma and palea or through the apical floret mouth. The
Additional keywords: deoxynivalenol, Gibberella zeae.
Fusarium head blight can cause serious losses in yield and quality of barley and wheat, especially when moisture is abundant in the first week or two after heads emerge from the flag leaf sheath $(23,26,27)$. In the United States, the principal head blight pathogen is Fusarium graminearum Schwabe (teleomorph Gibberella zeae (Schwein.) Petch). Airborne ascospores produced by the fungus in crop residues directly infect the barley or wheat head. Macroconidia also are produced by the fungus and can infect heads, giving infection levels similar to those from ascospores $(25,27)$. However, the pathways of infection and spread in the head are only partially described (3). Each floret in the barley or wheat head is enclosed by a lemma and palea which have thickwalled epidermal and hypodermal cells on their exterior surfaces $(3,18,20,31)$. These walls act as barriers against direct penetration of the fungus. In a comprehensive histological investigation of head blight in wheat, Pugh et al. (20) found that the thick-walled epidermal cells of the lemma and palea prevent direct penetration by $F$. graminearum. In contrast, the cells on surfaces within the floral cavity were thin-walled and readily susceptible to invasion.

Pugh et al. (20) focused mainly on advanced stages of floret infection, but also reported that anthers caught in the floret mouth "showed the first sign of infection" preceding lesion formation in the floret. In contrast, Tu (30) noted that the initial point of infec-

Corresponding author: S. M. Lewandowski; E-mail address: lewan009@umn.edu

DOI: 10.1094/PHYTO-96-0567

This article is in the public domain and not copyrightable. It may be freely reprinted with customary crediting of the source. The American Phytopathological Society, 2006. tion in wheat was frequently through the "glumes," apparently meaning the lemma and palea. He concluded that the anther was not necessarily the "court of initial infection." Several investigators have shown that wheat anthers are colonized readily by $F$. graminearum or that infection levels are higher when anthers are present than absent (17). Anthers contain substances that promote growth or alter branching patterns of $F$. graminearum (6, 28,29). However, the importance of the anther as an avenue of fungal entry into florets has not been evaluated in relation to other possible avenues in either wheat or barley.

Since the reports of Pugh et al. (20) and Tu (30), several investigators have studied fungus development within florets, usually by injecting macroconidia of $F$. graminearum or other head blight fungi directly into the floret interior $(7,8,16,31,32)$. This assured infection of the interior but did not address pathways of entry into florets. However, Kang and co-workers followed early stages of fungal development with scanning electron microscopy (SEM) on wheat sprayed with macroconidia of $F$. culmorum (9) and $F$. avenaceum (12), two head blight pathogens. As Pugh et al. (20) had found, the fungus developed more abundantly on interior than on exterior surfaces and did not penetrate the exterior surface. In some instances, hyphae on the exterior surface grew to the apex of the lemma and over the edge, apparently gaining entry into the floret. However, the spray inoculation procedure placed macroconidia not only on the floret exterior but also on interior surfaces where the spores were observed to germinate. Whether the hyphae that later proliferated within the floret originated in part from hyphae entering at the floret apex was not determined.

Another postulated pathway of floret entry is the stomate. Hyphae of $F$. graminearum entered stomates of the wheat glume 
which subtends wheat spikelets (19). Hyphae of F. culmorum entered stomates within wheat florets (9), whereas hyphae of F. avenaceum did not (12). Whether entry through stomates on the floret exterior leads to tissue colonization has not been determined.

In barley, pathways of floret entry by head blight pathogens have not been investigated. As in wheat, external floret surfaces have thick-walled epidermal cells (18) which are unlikely to be penetrated, in contrast to the thin-walled cells in the floret interior. Here, we report results of head blight inoculation experiments done with barley in 2001 and 2002, in which the anatomy of uninfected florets is described and the distribution of fungal colonies and lesions on exterior and interior surfaces of infected florets is documented. The experiments were done in the field to avoid the excessive mycelial growth on floret surfaces that occurs under moist conditions in incubators or the greenhouse (unpublished observations). The results give a comprehensive view of fungal and lesion development in head blight of barley and show how the fungus gains access to the floret interior.

\section{MATERIALS AND METHODS}

Plots. Experiments were carried out in 2001 and 2002 at St. Paul, MN, following the plot design, inoculation procedures, and mist irrigation described by Dill-Macky (5) for screening of wheat and barley lines for resistance to Fusarium head blight. The plots were planted, inoculated, and irrigated in conjunction with head blight evaluation plots. Each plot was 1.2 by $2.4 \mathrm{~m}$, with four 2.4-m rows of Robust, a head-blight-susceptible, six-rowed spring malting barley cultivar widely grown in Minnesota. Plots were seeded on 30 April 2001 and on 30 April and 1 May 2002. Some uninfected specimens used to illustrate floret anatomy were grown in a plant growth chamber as described elsewhere (13).

Inoculation. Macroconidia used for inoculum were grown from four to six isolates of $F$. graminearum obtained in 2000 from commercial crops of wheat and barley in northwestern Minnesota for use in 2001, and similarly in 2001 for use in 2002. Macroconidia were produced by growing the isolates for 6 days in petri dishes on mung bean agar, as described by Dill-Macky (5). Macroconidia were collected in aqueous suspension in 1-liter bottles, adjusted to a concentration of 800,000 spores $/ \mathrm{ml}$ as measured with a hemacytometer, and stored at $-80^{\circ} \mathrm{C}$ for 1 to 4 months. In separate trials, spores prepared and stored using these procedures had germination percentages of 91 to $100 \%$ (unpublished data).

Plants were inoculated in midafternoon on 25 June 2001 and 29 June 2002 when plants were at Zadoks' growth stage 59 (33) and $90 \%$ of heads had emerged from the flag leaf sheath. Inoculum was thawed and diluted to final concentrations of 50,000 and 100,000 macroconidia/ml (except as noted). Tween 20 (SigmaAldrich, St. Louis) was added to a final concentration of $2 \mathrm{ppm}$. Inoculum was applied to most plots with a backpack sprayer pressurized with compressed $\mathrm{CO}_{2}$ at $276 \mathrm{kPa}$. Spray was directed downward from a flat fan nozzle (SS 80015; Teejet, Wheaton, IL) $\approx 30 \mathrm{~cm}$ above the plant heads. Each row was sprayed once, with the nozzle moving at a speed of $0.25 \mathrm{~m} / \mathrm{s}$, which delivered inoculum at $31 \mathrm{ml} / \mathrm{m}$ of row. To assist in sampling of heads as described later, 60 to 100 plants with fully emerged heads were marked with tape or red ink immediately before plants were inoculated. In 2002, inoculum was applied at $83 \mathrm{kPa}$ to heads of marked plants with a hand-held airbrush (Type H, No. 5; Passch Co., Chicago) with its nozzle held $10 \mathrm{~cm}$ from the head. Heads were rotated while $\approx 0.7 \mathrm{ml}$ of spray was directed to the sides of each for a total of $4 \mathrm{~s}$.

Irrigation. Immediately after inoculation, plots were irrigated for 18 to $20 \mathrm{~min}$ with a fine mist dispensed horizontally from nozzles $\approx 25 \mathrm{~cm}$ above the plant canopy. Starting the evening of inoculation and continuing for 12 to 13 days after inoculation (DAI), plots were mist irrigated for durations of 9 or $18 \mathrm{~min}$ at 1-h intervals from 17:00 to $21: 00$ and 4:00 to 6:00 local daylight savings time. Each 9-min application interval dispensed $\approx 0.5 \mathrm{~mm}$ of water over the plot surface; each 18-min application dispensed $\approx 1 \mathrm{~mm}$. In addition to irrigation, one period of rain occurred 4 DAI in 2002 when precipitation totaled $11 \mathrm{~mm}$.

Head selection. From each inoculated plot, heads from five plants were collected on selected days of sampling: 1 to $12 \mathrm{DAI}$ in 2001 and 1 to 6 DAI in 2002. Heads were taken from a principal culm (stem) of each plant. Plants within $15 \mathrm{~cm}$ of plot borders were not used. Most heads selected at 1 to 3 DAI were from plants marked as fully emerged at the time of inoculation. Thereafter, heads with one or more visible lesions were selected if available. Heads were collected with $\approx 10 \mathrm{~cm}$ of stem attached and placed in sealed plastic bags for transport to the laboratory. For observation of lesions, florets were examined the day of harvest. For observation of mycelium, florets taken from heads were fixed on the day of harvest in lactophenol blue as described later. For illustration of floral anatomy, uninfected heads from field plots or a growth chamber were selected to represent heads at the time of inoculation and 5 to 6 days after inoculation.

Floret selection. In 2001, samples for observing lesions were harvested as triplets (Fig. 1A and B) from single rachis nodes (Fig. 1C), located in the mid one-third portion of each of five heads per plot per day, with bias for triplets with one or more visible lesions if present. All three florets of each triplet were dissected and examined for lesions. For observation of mycelium on floret surfaces, an additional four florets from the middle of each head were collected, each usually from a different node. In 2002, four florets were taken from each of five heads/plot/day, each usually from a different node. Samples collected 1 to 3 DAI in 2002 were used only for observation of mycelium in fixed specimens from airbrush-inoculated heads. Samples collected 4 to 6 DAI were used only for observation of lesions on fresh specimens. These were from heads inoculated from overhead with the $\mathrm{CO}_{2}$-powered backpack sprayer.

Observation of dissected florets. For observation of lesions and mycelial colonies, florets were snapped off the rachis with forceps. The apex of the awn was cut off $\approx 5 \mathrm{~mm}$ above the lemma (Fig. 1D and E) and discarded. Lesions were observed in unfixed florets on the day of harvest. Mycelial colonies were observed after florets were fixed and stained in screw-capped 1-ml cryotubes containing one part lactophenol blue solution (Fluka Chemical, Buchs, Switzerland) to two parts ethyl alcohol. The solution was heated to boiling and poured over the florets in the tubes. Each tube contained 10 to 20 florets, depending on stage of development. Florets were kept in staining solution overnight at room temperature, then incubated at $4^{\circ} \mathrm{C}$ for 1 to 2 weeks. Florets then were rinsed twice in $50 \%$ ethyl alcohol for $15 \mathrm{~min}$, followed by two 10-min rinses in water obtained from a MilliQ Water System (Millipore Co., Billerica, MA). Florets then were placed in 20-ml glass scintillation vials, covered with $25 \%$ aqueous glycerol solution, and stored for 1 to 4 weeks before examination. To avoid excessive presence of contaminating fungi and miscellaneous debris, samples harvested later than 8 DAI were not included in tables and graphs showing numbers of florets with colonies.

Both fresh and fixed florets were dissected by cutting off the floret stalk 2 to $3 \mathrm{~mm}$ above the rachis, slightly above the site of attachment of the lemma, palea, and caryopsis (Fig. 1C, dashed line). The excised stalk was retained for examination. Surfaces of the awn, palea, and lemma were designated abaxial or adaxial with respect to the floret axis; surfaces of the caryopsis were designated abaxial and adaxial with respect to the rachis of the head. Surfaces of fresh floret parts were examined for lesions with the aid of a dissecting microscope. Fixed floret parts were mounted in $25 \%$ glycerol on glass slides and examined for mycelial colonies with the dissecting microscope or a Zeiss Standard compound microscope. The shape, size, and location of lesions and colonies were recorded on diagrams of floret parts for the 
following surfaces: (i) the adaxial (ventral) and abaxial (dorsal) surfaces of the awn base (Fig. 1D and E), (ii) the adaxial (interior) and abaxial (exterior) surfaces of the lemma and palea (Fig. 1D and E), (iii) the abaxial surface of the caryopsis facing the lemma
(Fig. 1F) and adaxial surface facing the palea (not shown), (iv) apical and basal exposed faces of the 2- to 3-mm excised stalk (the basal face was exposed where the floret was broken away from the rachis and the apical face where the stalk was cut from
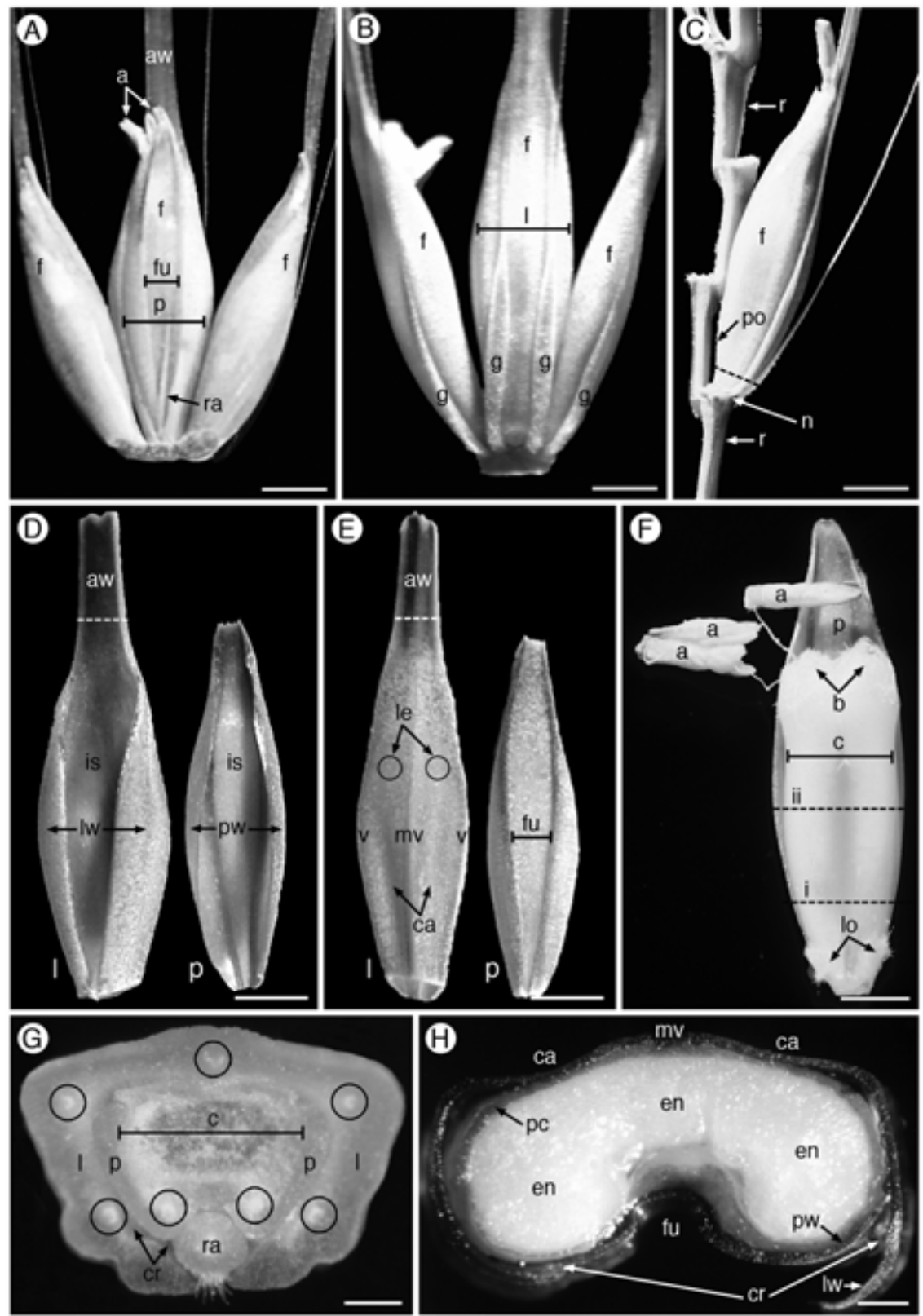

Fig. 1. Anatomical features pertinent to head blight development in florets of uninfected six-rowed barley. Florets were from $\mathbf{A}$ to $\mathbf{F}$, the field or $\mathbf{G}$ and $\mathbf{H}$, a growth chamber. Florets were from Robust barley, except Stander (D and E). Plants were harvested at a stage of development equivalent to plants at time of inoculation (D, E, and G) or 5 to 6 days after inoculation (A to $\mathbf{C , ~ F , ~ a n d ~} \mathbf{H})$. Specimens were unfixed except floret of $\mathbf{H}$. See appendix for glossary of terms used. A, Triplet of florets (f) produced on a rachis node, typical of six-rowed barley. View of the central floret surface that faced the rachis, showing exposed portion of the palea (p) with ventral furrow (fu), which runs the length of the floret, rachilla (ra) at base of the furrow, partially exserted anthers (a), and adaxial surface of awn (aw). Bar $=3.0 \mathrm{~mm}$. B, Triplet of florets as in A. View of the central floret surface that faced away from the rachis, showing the exterior (abaxial) surface of the lemma (1). Each floret has two glumes $(\mathrm{g})$ as visible for the central floret. Bar $=3.0 \mathrm{~mm}$. C, Central floret (f) of triplet on node (n) of rachis (r). Other florets were removed. A sheltered pocket (po) lies between rachis and basal one-fourth of the floret. Dashed line indicates cut made to excise floret stalk. Bar $=3.0 \mathrm{~mm}$. D and E, Surfaces of detached lemma (l) and palea (p). D, Interior (adaxial) surfaces (is). Recurved wings of lemma (lw) and palea (pw) partially block view of interior edges. The wings of the lemma overlap the wings of the palea in the intact floret (as shown in cross section in Figs. 1H and 2). Dashed line delineates awn (aw) base from attached lemma. Bar $=3 \mathrm{~mm}$. E, Exterior (abaxial) surfaces. Veins (v) border concave areas (ca) on each side of the lemma midvein (mv). A ventral furrow (fu) extends the length of the palea. Dark brown lesions develop in indicated zones (le) in some infected florets. Bar $=3.0 \mathrm{~mm}$. F, Caryopsis (c) nested in half shell of palea (p) 5 days after time of inoculation. Three anthers (a) are fully exserted. Brush apex (b) extends toward mouth at apex of floret. Two lodicules (lo) are at base of caryopsis. Dashed lines (i and ii) show location of cross sections from similar florets in $\mathbf{G}$ and $\mathbf{H}$. Adapted from Bushnell et al. (3). Bar $=2.0 \mathrm{~mm}$. G, Basal free-hand section at dashed line i of $\mathbf{F}$, floret at time of inoculation. The overlapping lemma (l) and palea (p) are loosely joined, providing crevices (cr) for possible fungal entry. The rachilla (ra) is located at the base of opening of the lemma, as in A. The lemma has five vascular bundles (circled); the palea has two. Bar $=0.3 \mathrm{~mm}$. H, Mid-cross section of fixed and stained floret 5 days after time of inoculation. Position of section indicated by dashed line ii in $\mathbf{F}$. The overlapping wings of the lemma (lw) and palea (pw) (with furrow [fu]) together cover the developing caryopsis, which consists of the pericarp (pc) enclosing endosperm (en). On each side of the floret, a crevice (cr) between the overlapping wings of the lemma and palea offers a potential pathway for fungal invasion. The midvein (mv) of the lemma forms a "keel," bordered on each side by thin concave areas (ca), sites of lesions as described elsewhere. Figure 2 provides diagram of cross section. Adapted from Bushnell et al. (3). Bar $=0.5 \mathrm{~mm}$. 
the floret) (Fig. 1C), and (v) lodicules (Fig. 1F). In addition, the presence of mycelium on anthers was noted. A floret was considered to have one or more colonies when the fungus colonized discrete areas on the floret surface and also if the fungus was present as a widespread mycelial network. Aborted or fully brown florets without visible lesion borders were excluded from tabulated results for numbers of florets with lesions.

Color photographs were taken with $35-\mathrm{mm}$ cameras with slide film (Kodak Ektachrome 160T, Tungsten) or print film (Kodak 200, Bright Sun \& Flash, or Kodak 400, Max Versatility). Other color photos were taken with a Nikon Model DXM1200 digital camera attached to a Zeiss standard microscope. Slide and print images were scanned digitally.

\section{RESULTS}

Temperature. Temperatures were obtained from a field plot weather station located $\approx 350 \mathrm{~m}$ from our head blight plots. The maximum temperature on the day of inoculation was $36^{\circ} \mathrm{C}$ in 2001 and $34^{\circ} \mathrm{C}$ in 2002 . This was 6 to $9^{\circ} \mathrm{C}$ above average daily maxima.

In 2001 , temperatures remained $\approx 3$ to $5^{\circ} \mathrm{C}$ above average for the first $5 \mathrm{DAI}$, then fluctuated mostly below average at 6 to $10 \mathrm{DAI}$ before returning to $3^{\circ} \mathrm{C}$ above average at 11 to $12 \mathrm{DAI}$. In 2002, temperatures were 6 to $8^{\circ} \mathrm{C}$ above average 1 and 6 DAI, with near average temperatures 2 to 5 DAI. In addition, temperatures were $5^{\circ} \mathrm{C}$ above average 4 to 7 days before inoculation in both 2001 and 2002. In both years, minimum daily temperatures were well above average, especially during the first 4 to 5 DAI.

Anatomy of the barley floret. The principal anatomical features of the field-grown Robust barley florets dissected in our investigation are shown in Figure 1. As is typical of six-rowed barley cultivars, a triplet of florets (Fig. 1A and B) was borne on each node of the rachis (Fig. 1C) of the head. At the base of each floret were two narrow vestigial glumes (Fig. 1B). These rarely showed signs or symptoms of disease. The main body of the floret consisted of a boat-shaped lemma (Fig. 1B, D, and E) whose "keel" faced away from the rachis, and a boat-shaped palea with a furrow, which faced the rachis (Fig. 1A, D, and E). The edges (wings) of the lemma overlapped the edges of the palea, leaving an opening (Fig. 1A and D), which exposed much of the palea surface facing the rachis (Fig. 1A). The furrow in this exposed area extended from base to apex of the palea (Fig. 1A and E). This was located over the ventral furrow of the developing caryopsis, as described by Briggs (2). The furrow of the palea was bordered on each side by a prominent vascular bundle. A sheltered pocket, located between the base of this furrow and the rachis (Fig. 1C), collected moisture and debris in the field-grown barley. This pocket frequently was colonized with fungal mycelium in inoculated plants, as described later. The portion of the rachilla extending apically above the level of palea attachment was located in this sheltered pocket (Fig. 1A). It was covered with thick-walled hair cells and was not observed to be colonized by $F$. graminearum in our experiments.

The caryopsis developed rapidly after fertilization, enlarging to fill the floral cavity by 5 to 6 DAI (Fig. 1F). At 3 and 4 DAI in the experiment of 2001, the mouth of one floret each day was forced open by the developing caryopsis (Table 1), exposing shoulders of the caryopsis directly to possible fungal colonization. No shoulders were exposed by 6 DAI in 2002.

A crevice was located between the overlapping edges of the lemma and palea. This was prominent at the base of young florets (Fig. 1G). It was present, though less prominent, near the midsection of older florets (Fig. 1H), extending to the floret mouth where tips of the lemma and palea come together. The lemma and palea were separated easily from one another and from the caryopsis until $\approx 8 \mathrm{DAI}$, attesting to loose attachment between the structures.

Each of the two vascular bundles in the palea and five in the lemma (Figs. 1G and 2) was bordered on each side by a double row of stomates (not shown). These rows of stomates were present in the apical half of the lemma and palea, but sometimes did not extend to the floret base. On the exterior surface of the lemma, a prominent midvein (Figs. 1E and 2) formed the "keel" between two adjacent concave areas on the exterior surface of the lemma. Within these concave areas, two unusually thin, semitransparent areas (Fig. 1E) delineated lesions in some infected florets.

Each floret had three anthers (Fig. 1F). These anthers were partially or fully exserted from the floret mouth at the time of inocu-

TABLE 1. Number of florets with mycelial colonies on indicated floret parts after inoculation with Fusarium graminearum in field experiments in 2001 and $2002^{\text {a }}$

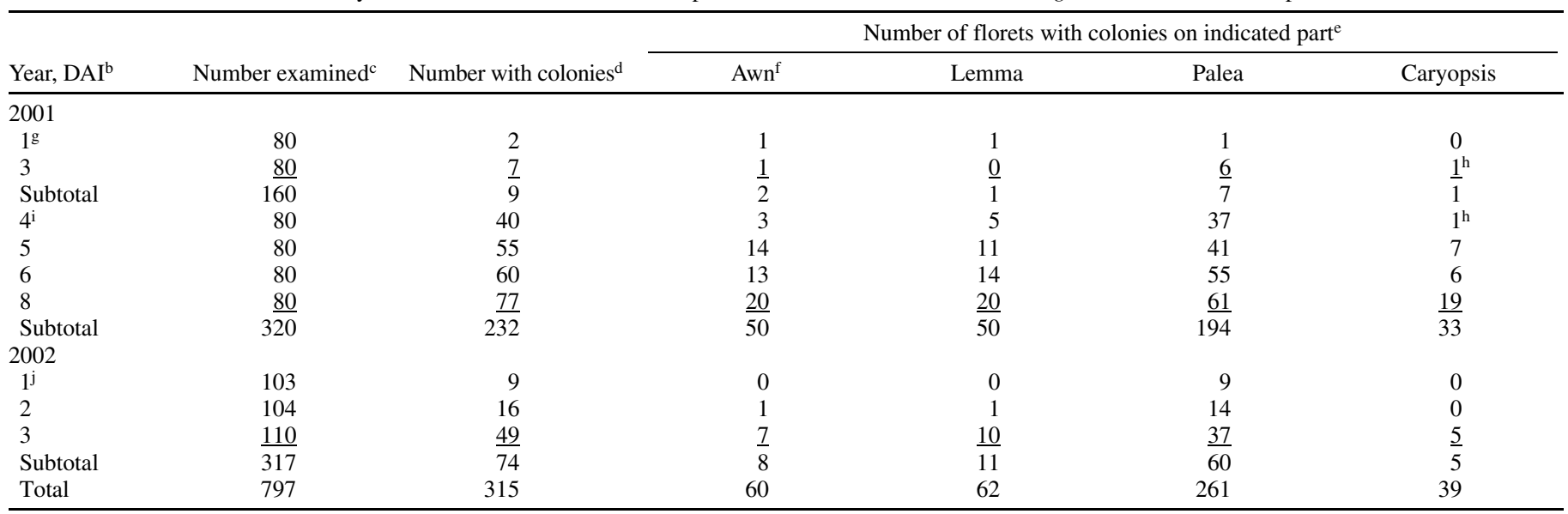

${ }^{a}$ Florets were fixed and stained with lactophenol blue. Putative Alternaria colonies not included.

${ }^{\mathrm{b}} \mathrm{DAI}=$ days after inoculation.

${ }^{c}$ Number of florets examined. Infertile florets not included.

${ }^{\mathrm{d}}$ Total number of florets with colonies.

${ }^{\mathrm{e}}$ Florets often had colonies on more than one floret part.

${ }^{\mathrm{f}}$ Colonies were on awn's adaxial surface, which is continuous with interior (adaxial) surface of the lemma.

g Florets sampled 1 and 3 DAI in 2001 were from triplets selected at random.

h Brush apex of caryopsis exposed.

${ }^{i}$ Florets sampled at 4 to 8 DAI in 2001 were from triplets usually showing one or more lesions.

j Florets sampled 1 to 3 DAI in 2002 were harvested singly and selected at random. 
lation. Each anther was nearly empty, having dehisced pollen within the floret before exsertion. As described later, anthers in the floret mouth sometimes were colonized by mycelium of F. graminearum.

The lemma and palea had thick-walled epidermal cells on exterior surfaces, as shown for the lemma (Fig. 3). Underlying the epidermis were two or three layers of thick-walled hypodermal cells. In contrast, the interior epidermis and underlying layers were thin-walled (Fig. 3).

Overview of floret samplings. Generally, the numbers of florets with colonies or lesions were not greatly different whether heads were inoculated with inoculum containing 50,000 or 100,000 macroconidia/ml (or 25,000 in one plot in 2002) (data not shown). Likewise, results were similar with irrigation applied for 9 or 18 min per application (data not shown). In view of the low number of useful samples obtained at some sampling times, especially at 1 to $3 \mathrm{DAI}$, we combined results for all concentrations of inoculum and for both irrigation schedules for presentation.

In the field experiment of 2001, in which inoculum was applied to all plots as an overhead spray, only $2 \%$ of florets had visible lesions at 13 DAI, when final disease incidence was assessed. At 1 to $3 \mathrm{DAI}$, when florets harvested as triplets were selected randomly, $6 \%$ of dissected florets had mycelial colonies (Table 1); $4 \%$ had one or more lesions (Table 2). In this period, sampling was random; there were no macroscopic signs or symptoms to assist in selection of infected florets. At 4 DAI and later in 2001, florets were taken from triplets with one or more lesions visible in the field, if available. For the period 4 to $8 \mathrm{DAI}, 73 \%$ of sampled florets had colonies (Table 1), and 13\% of florets had lesions (Table 2). At 10 and 12 DAI, $F$. graminearum could no longer be distinguished from contaminating fungi, whereas $37 \%$ of florets had lesions (Table 2). At 5 to 12 DAI, a few florets were entirely chlorotic, although discrete lesions remained visible (Table 2). At 8 to 12 DAI, a few florets were entirely brown, such that individual lesions were no longer visible (Table 2). Chlorotic and necrotic florets were not present in noninoculated plots.

In the 2002 experiment, heads to be sampled for colonies 1 to 3 DAI were inoculated individually with an airbrush sprayer to maximize infection success. Colonies were present in $23 \%$ of florets sampled in the 3-day period (Table 1). All florets sampled for lesions 4 to 6 DAI had lesions because only heads showing

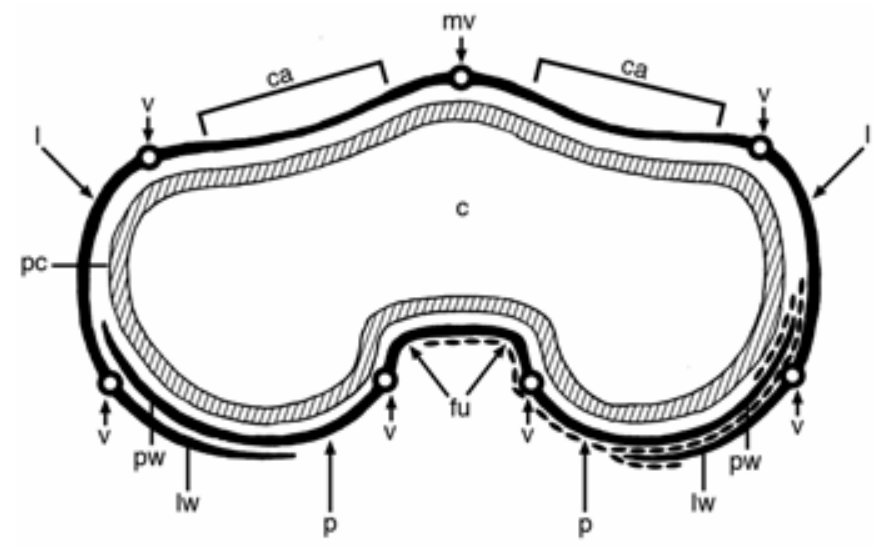

Fig. 2. Diagram of barley floret cross section (as in Fig. 1H), showing lemma (l) and palea (p), overlapping wings of lemma (lw) and palea (pw), veins (v), concave areas (ca) beside midvein (mv) of the lemma, and pathways of Fusarium graminearum spread (dashed lines) from the palea furrow (fu) to outer and interior surfaces of the floret. The fungus grew from the furrow to the edge of the lemma wing (lw) and then either onto the exterior (abaxial) surface of the lemma wing or into the crevice between the wings of the lemma and palea. In a few cases, the fungus extended through the crevice to the floret interior, where it colonized the interior (adaxial) surface of the palea wing and had access to the pericarp (pc) on the surface of the caryopsis (c). lesions in the field were selected (Table 2). These were from plants that received overhead spray inoculation as in 2001. As assessed at 12 DAI in the field in $2002,17 \%$ of all florets had lesions, indicating that conditions were more favorable for infection than in 2001 , when only $2 \%$ of florets had lesions at $13 \mathrm{DAI}$, as described earlier.

Description of colonies. Macroconidia from inoculum were observed to germinate on exterior floret surfaces (Fig. 4A), producing hyphae that grew in various directions across floret surfaces (Fig. 4B). Hyphae sometimes grew near or over stomates, but were not observed entering them. The hyphae formed sparsely branched mycelial colonies appressed to floret surfaces (Fig. 4C, $\mathrm{D}$, and E). Some colonies were restricted in spread with fairly discrete borders (Fig. 4C). Others spread widely, coalescing with other colonies to form continuous mycelial networks (Fig. 4E). Colonies on the lemma exterior generally were restricted in diameter (Fig. 4C), but a few stretched laterally to the crevice between the palea and lemma. Only rarely did colonies extend apically to the floret mouth on the lemma exterior.

Colonies in the basal portion of the furrow of the palea were much more abundant than elsewhere, often covering the furrow base (Fig. 4D and E). These were a source of mycelium growing laterally to the crevice between palea and lemma, as described later. On the caryopsis surface, hyphae tended to be oriented basipetally from apex to base (Fig. 4F), with less branching than on surfaces of the lemma and palea. As described later, mycelial mats on the caryopsis surface were sometimes pink. On surfaces of partially exserted anthers, the fungus produced fluffy white mycelium (Fig. 4G).

Macroconidia from inoculum (Fig. 4A and B) rarely were found later than 3 to 4 DAI except for a few poorly stained remnants of collapsed conidia (not shown). On the other hand, intact macroconidia characteristic of $F$. graminearum occasionally were present on floret surfaces within colonized areas at 6 DAI, singly or in groups of two to three spores, an indication that the fungus was newly producing macroconidia. Pollen grains sometimes were present on floret surfaces (Fig. $4 \mathrm{H}$ ). By 10 to $12 \mathrm{DAI}$, soil particles and other debris also accumulated (Fig. 4H and I). In addition, spores characteristic of Alternaria spp. and associated hyphae were present in increasing numbers at 10 to12 DAI. These hyphae (Fig. 4I) were wider than those of $F$. graminearum observed in laboratory experiments, produced branches at higher angles (often 90\%), and branched at shorter intervals along

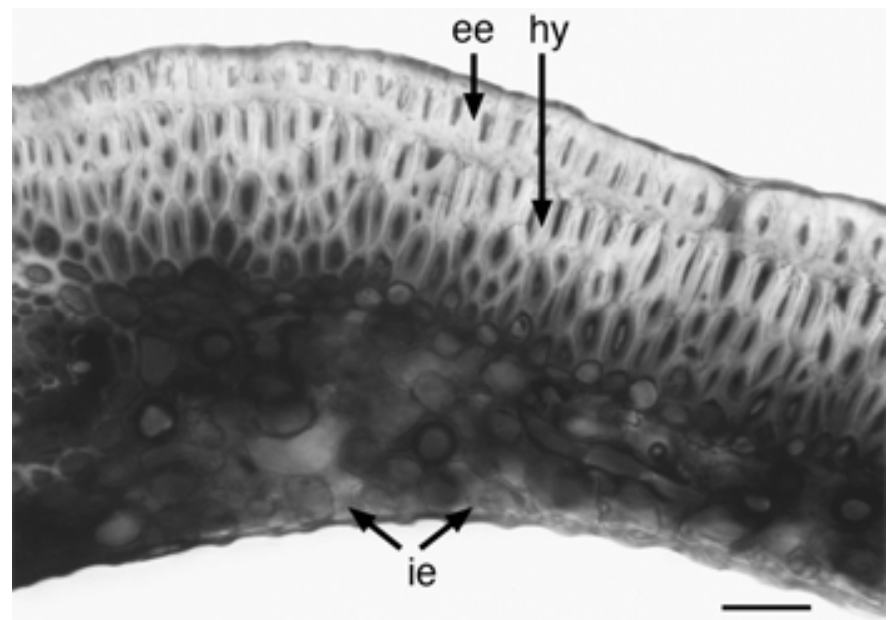

Fig. 3. Cross section of a barley lemma, stained with lactophenol blue. Cells of the exterior (abaxial) epidermis (ee) and the hypodermis (hy) were thick walled. Cells of the interior (adaxial) epidermis (ie) were thin walled. The lemma was sectioned $\approx 2 \mathrm{~mm}$ above the floret stalk from a floret harvested from a head 7 days after it emerged from the flag leaf sheath. Growth chamber-grown plant of Robust barley. 
hyphae. In 2001, putative colonies of Alternaria spp. were present in $5 \%$ of florets at $8 \mathrm{DAI}, 8 \%$ at $10 \mathrm{DAI}$, and $18 \%$ at $12 \mathrm{DAI}$. In $2002,26 \%$ of florets had such colonies in a final assessment at 12 DAI.

Number and location of mycelial colonies. Of 480 florets sampled at 1 to $8 \mathrm{DAI}$ in 2001 and 317 florets sampled at 1 to 3 DAI in 2002, 315 had one or more mycelial colonies attributed to F. graminearum (Table 1). Of these 315 florets, 261 had one or more colonies on the palea, compared with 62 on the lemma, 60 on the awn, and 39 on the caryopsis (Table 1). Numbers of florets with colonies on each floret part differed except for nearly equal numbers with colonies on the lemma and awn (Table 1). In comparisons of florets with colonies on exterior and interior surfaces (Fig. 5), somewhat more florets had colonies on exterior than interior surfaces 4 to 6 DAI in 2001. Otherwise, numbers were similar on both surfaces in 2001 (Fig. 5A) and 2002 (Fig. 5B).

On the palea, in contrast, many more florets had colonies on exterior than on interior surfaces in both years (Fig. 5C and D). The exterior colonies were located principally near the base of the palea furrow (Fig. 4D and E). Mycelium within the furrow often extended onto the adjacent surface of the palea (Fig. 2). This was observed in 6 of 67 florets at 1 to 3 DAI, 30 of 133 at 4 to 6 DAI, and 24 of 61 at 8 DAI for combined data from 2001 and 2002. Once out of the furrow, the mycelium spread laterally over the palea surface to the edge of the lemma, growing either onto the exterior surface of the lemma or into the crevice between the palea and lemma (Fig. 2). While traversing the crevice, the fungus usually grew on the palea surface facing the crevice. The position of mycelium as it entered the floret cavity was difficult to assess after the palea and lemma were separated; however, in a few cases, the mycelium was seen to colonize the interior (adaxial) surface of the palea (Fig. 2).

For the 60 florets with awns colonized in 2001 and 2002 (Table 1; Fig. 6A), nearly all colonies were on the concave, adaxial surface. On 34 florets, the mycelium on the adaxial surface of the awn extended onto the interior (adaxial) surface of the lemma.
We compared numbers of florets with mycelial colonies on apical and basal halves of the lemma, palea, and caryopsis (Fig. $6 \mathrm{~B}$ to $\mathrm{G})$. On the lemma exterior, numbers with colonies did not differ consistently between apical and basal halves (Fig. 6B). On the lemma interior, more florets had colonies on the apical than basal half (Fig. 6C). This was consistent with the spread of mycelium downward from the awn, as described earlier. On the palea exterior, much larger numbers of florets had colonies on the basal than the apical half (Fig. 6D). The basal colonies were mainly in the furrow, as noted earlier. On the palea interior, the few colonies present usually were on the apical half (Fig. 6E).

The caryopsis was colonized principally on the apical half, on both the side facing the lemma (Fig. 6F) and the side facing the palea (Fig. 6G). Note that the number of florets with colonies on the side of the caryopsis facing the lemma (Fig. 6F) was similar to the number colonized on the lemma interior (Fig. 6C), which, in turn, was greater than the number of florets with colonies on the palea interior (Fig. 6E). These results indicate that the interface between the interior surface of the lemma and caryopsis formed a favored channel for fungus spread basipetally within the floret.

Mycelial colonization of anthers. To determine the frequency of anther colonization, we used fresh florets that also were used for locating lesions (Table 2) as presented later. Mycelium on the fresh, unfixed anthers was readily visible as white to brown cottony masses (Fig. 4G). Of 352 florets examined 4 to 12 DAI, 117 had anthers caught in the floret mouth and 191 had exserted anthers present on the outer floret surface (Table 3). Of all 308 florets with anthers either caught or exserted but present, only 18 had anthers colonized with mycelium (Table 3 ). Ten of these florets had lesions on the palea, three of which had lesions on the lemma. Therefore, in these 10 florets, anthers may have facilitated infection leading to lesion formation. Unfortunately, we could not compare anther colonization directly to floret colonization because different methods and samples were used for each. However, the total number of fresh florets with colonized anthers, 18, was small compared with the total number of fresh florets with

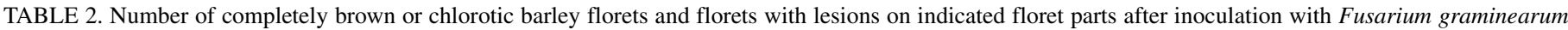
in field experiments in 2001 and 2002

\begin{tabular}{|c|c|c|c|c|c|c|c|c|c|}
\hline \multirow[b]{2}{*}{ Year, DAI ${ }^{\mathrm{a}}$} & \multicolumn{3}{|c|}{ Number of florets } & \multicolumn{6}{|c|}{ Number of florets with discrete lesions on indicated floret part ${ }^{\mathrm{b}}$} \\
\hline & Examined ${ }^{\mathrm{c}}$ & Brown $^{\mathrm{d}}$ & Chlorotic $^{\mathrm{e}}$ & Entire floret & Awn & Lemma & Palea & Caryopsis & Stalk $^{\mathrm{f}}$ \\
\hline \multicolumn{10}{|l|}{2001} \\
\hline $1^{\mathrm{g}}$ & 60 & 0 & 0 & 0 & 0 & 0 & 0 & 0 & 0 \\
\hline 2 & 60 & 0 & 0 & 2 & 0 & 1 & 1 & 0 & 0 \\
\hline 3 & $\underline{60}$ & $\underline{0}$ & $\underline{0}$ & $\underline{5}$ & $\underline{1}$ & $\underline{5}$ & $\underline{2}$ & $\underline{0}$ & $\underline{0}$ \\
\hline Subtotal & $1 \overline{80}$ & 0 & $\overline{0}$ & $\overline{7}$ & $\overline{1}$ & $\overline{6}$ & $\overline{3}$ & 0 & $\overline{0}$ \\
\hline $4^{\mathrm{h}}$ & 59 & 0 & 0 & 4 & 0 & 2 & 4 & 0 & 0 \\
\hline 5 & 59 & 0 & 2 & 12 & 3 & 4 & 6 & 3 & 1 \\
\hline 6 & 58 & 0 & 1 & 11 & 2 & 4 & 7 & 4 & 1 \\
\hline 8 & $\underline{60}$ & $\underline{3}$ & $\underline{2}$ & $\underline{14}$ & $\underline{5}$ & $\underline{6}$ & $\underline{8}$ & $\underline{7}$ & $\underline{4}$ \\
\hline Subtotal & 236 & 3 & 5 & 41 & 10 & 16 & 25 & 14 & 6 \\
\hline 10 & 59 & 5 & 3 & 23 & 5 & 11 & 14 & 11 & 5 \\
\hline 12 & $\underline{57}$ & $\underline{0}$ & $\underline{4}$ & $\underline{20}$ & $\underline{0}$ & $\underline{8}$ & $\underline{11}$ & $\underline{11}$ & $\underline{9}$ \\
\hline Subtotal & 116 & 5 & 7 & 43 & 5 & 19 & 25 & 22 & 14 \\
\hline \multicolumn{10}{|l|}{2002} \\
\hline $4^{\mathrm{i}}$ & 41 & 2 & 3 & 41 & 0 & 39 & 27 & 17 & 11 \\
\hline 5 & 40 & 6 & 3 & 40 & 0 & 40 & 31 & 11 & 17 \\
\hline$\underline{6}$ & $\underline{24}$ & $\underline{3}$ & $\underline{3}$ & $\underline{24}$ & $\underline{0}$ & $\underline{14}$ & $\underline{24}$ & $\underline{12}$ & $\underline{16}$ \\
\hline$\overline{\text { Subtotal }}$ & $\overline{105}$ & $1 \overline{1}$ & $\overline{9}$ & $\overline{105}$ & $\overline{0}$ & $\overline{93}$ & $\overline{82}$ & $\overline{40}$ & $\overline{44}$ \\
\hline Total & 637 & 19 & 21 & 196 & 16 & 134 & 135 & 76 & 64 \\
\hline
\end{tabular}

a DAI = days after inoculation.

${ }^{\mathrm{b}}$ Florets often had lesions on more than one floret part.

c Florets examined fresh (not fixed or stained). Data do not include sterile florets.

d Fully brown florets which lacked visible discrete lesions. These were excluded from data for florets with discrete lesions.

e Fully chlorotic to light-brown florets. Discrete lesions visible against the chlorotic or light brown background are included in data for indicated floret parts.

${ }^{\mathrm{f}}$ Lesions visible only on exposed surface at ends of excised stalks.

g Florets examined 1 to 3 DAI were from triplets selected at random from heads known to be emerged at the time of inoculation.

${ }^{\text {h }}$ Florets examined 4 to 12 DAI (2001) were from triplets showing one or more lesions at harvest.

i Florets examined 4 to 6 DAI (2002) were harvested singly and showed one or more lesions. 

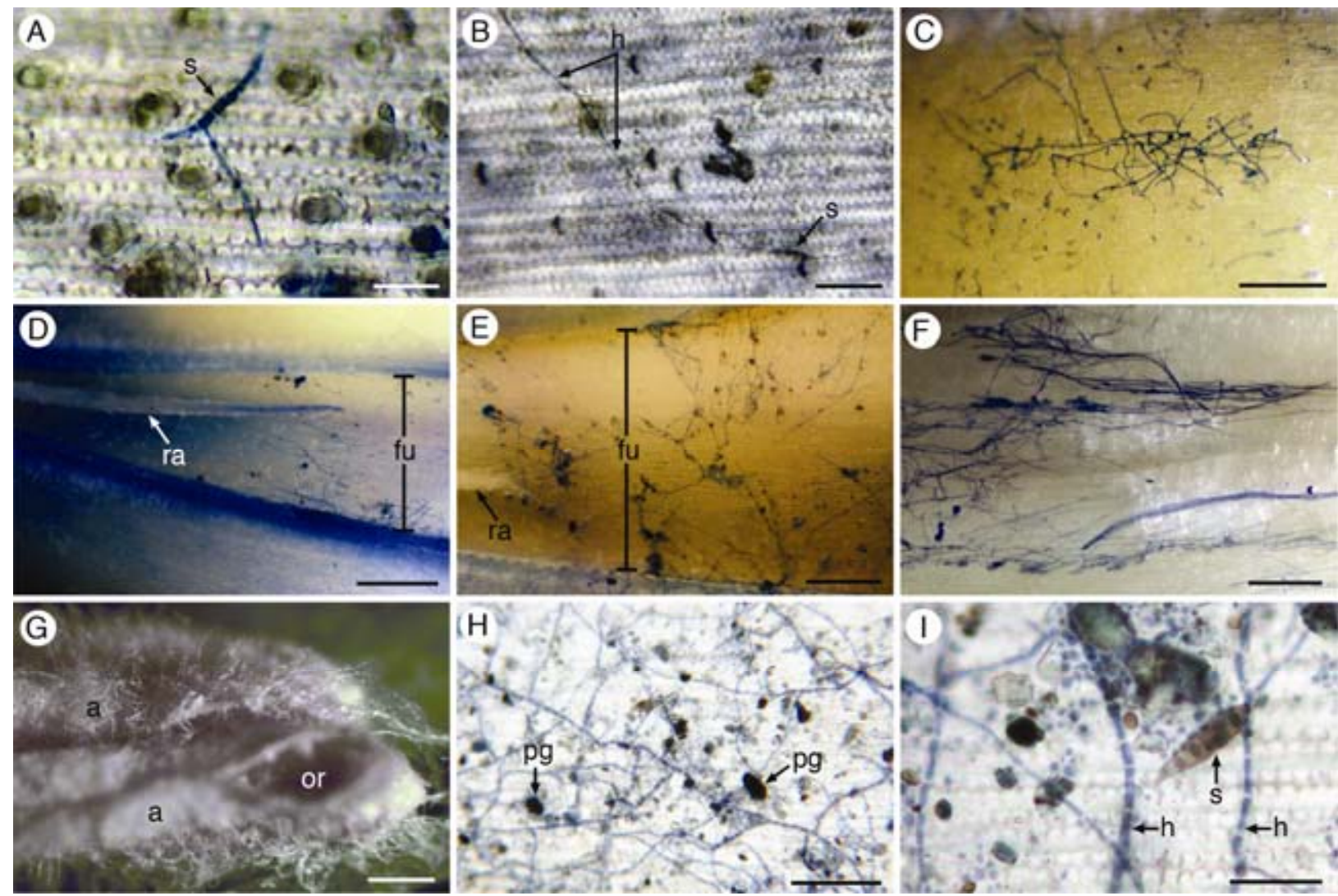

Fig. 4. Mycelium on surfaces of Robust barley florets inoculated with Fusarium graminearum. Florets were fixed and stained in lactophenol blue. All were from field specimens except in $\mathbf{F}$, which was from a growth chamber. A, Germinated macroconidium (s) on exterior (abaxial) surface of lemma, 6 days after inoculation (DAI). Bar $=30 \mu \mathrm{m}$. B, Hypha $(\mathrm{h})$ extending from germinating macroconidium across exterior surface of lemma, 2 DAI. Bar $=50 \mu \mathrm{m}$. C, Small mycelial colony on exterior surface of lemma, 12 DAI. Bar $=200 \mu \mathrm{m}$. D and E, Mycelial network in ventral furrow (fu) of palea in two florets. In both florets, the fungus is located near the base of the furrow, close to the apex of the rachilla (ra), 8 to 10 DAI. Bar $=400$ and $300 \mu \mathrm{m}$ in D and E, respectively. F, Mycelium on surface of caryopsis, 4 days after detached floret was inoculated with F. graminearum and incubated in a growth chamber. Mycelium extends basipetally from right to left. $\mathrm{Bar}=400 \mu \mathrm{m}$. G, Anthers (a) colonized by mycelium. The anthers were caught partially exserted in a floret mouth. Anthers have dehisced, leaving an empty colonized corpse with open orifice (or) near apex, 5 DAI. Bar $=400 \mu \mathrm{m}$. H, Mycelial network on external (abaxial) surface of palea furrow. Also present are pollen grains (pg) and miscellaneous smaller particles of dust and other debris, 12 DAI. Bar $=100 \mu \mathrm{m}$. I, Putative hyphae (h) and spore (s) of Alternaria spp. on exterior surface of palea, along with smaller diameter hyphae presumed to be $F$. graminearum. Various sized particles of debris are also present, $12 \mathrm{DAI}$. Bar $=30 \mu \mathrm{m}$.

2001
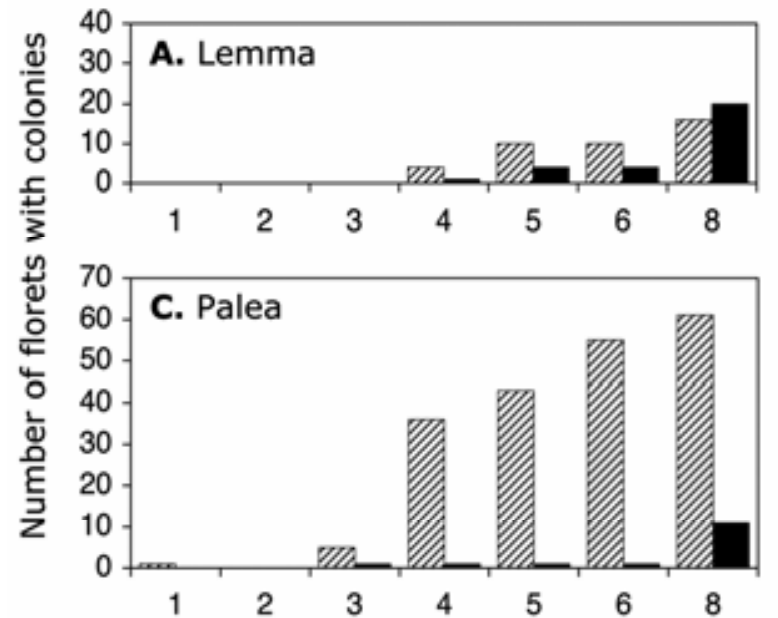

2002
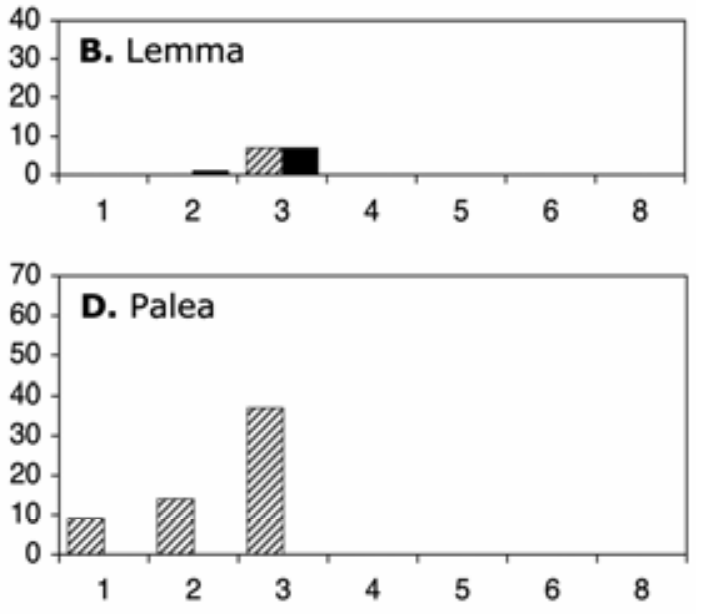

Days after inoculation

Exterior (abaxial) surface

Fig. 5. Number of barley florets with mycelial colonies of Fusarium graminearum on exterior (abaxial) or interior (adaxial) surfaces of the A and B, lemma and $\mathbf{C}$ and D, palea in field experiments of 2001 and 2002. Total number of florets examined daily was 80 in 2001 and 103 to 110 in 2002 (Table 1). Sampled 1 to 8 days in 2001; 1 to 3 days in 2002. Some florets had colonies on both exterior and interior surfaces of the lemma or palea. 
lesions, 84; in other words, anthers could have contributed to lesion formation in no more than $21 \%$ of florets with lesions.

Description of lesions. As assessed at 12 to 13 DAI, 2\% of florets had lesions in 2001 and $37 \%$ in 2002, as noted earlier. At this late stage, developing kernels often were dark reddish brown, as shown in a head with many infected kernels (Fig. 7A). However, infected kernels usually were fewer in number than shown in Figure 7A. In infected kernels, the lemma and palea appeared collapsed and dehydrated, adhering tightly to the underlying caryopsis. At this advanced stage, individual lesions often were not delineated, having spread and coalesced to cover the infected kernel entirely. Aborted florets (Fig. 7B) were shrunken and shriveled, often partially dark brown or black. Aborted florets and heavily infected florets without delineated lesions were excluded from data for number of florets with lesions.
At 2 to 3 DAI, lesions were pale green to chlorotic and $<1 \mathrm{~mm}$ in diameter. Lesions enlarged thereafter, as, for example, in 2001, when average lesion diameter was $3.1(0.5$ to 4.0$) \mathrm{mm}$ at 4 to $6 \mathrm{DAI}$ and $4.0(0.5$ to 5.0$) \mathrm{mm}$ at 8 to $12 \mathrm{DAI}$. Lesions at $4 \mathrm{DAI}$ and thereafter generally were of two types. In one type, each lesion had brown to dark reddish brown borders surrounding a central core, which was chlorotic (Fig. 7C and D), light brown (Fig. 7E and F), or light green (Fig. 7G). By 8 to 10 DAI, a few lesions (1 to 3\%) had a white (bleached) central core (not shown). Through 8 DAI, neither the central core nor border tissues appeared to be collapsed, whether viewed by eye or microscopically (Fig. $7 \mathrm{H}$ ). The second type of lesion was without a border and was present 4 to 12 DAI. These lesions consisted of a generally brown to dark brown area (Fig. 7I, J, and K). Again, the lesions did not appear collapsed through 8 DAI. Lesions on the caryopsis
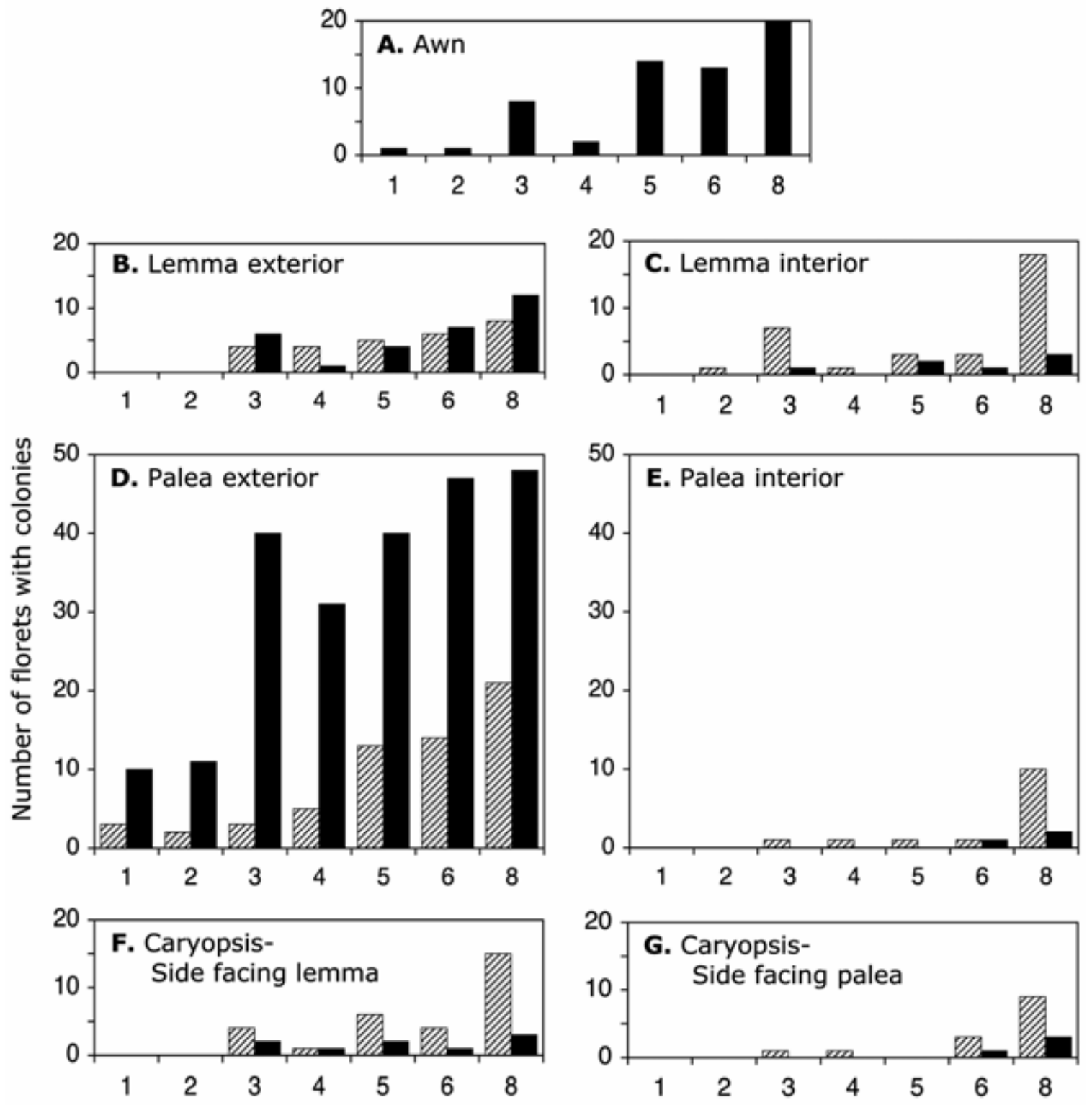

Days after inoculation

$$
\text { Apical WIIIIA Basal }
$$

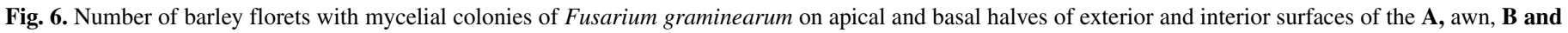

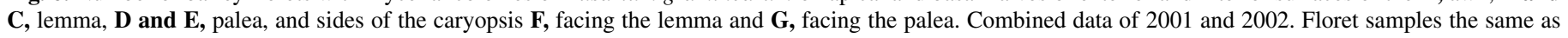
those described in Figure 5. Some florets had colonies on both apical and basal halves of the lemma and palea. 
generally were of the second type, without a distinct border, but were darker brown than lesions on the palea and lemma (Fig. 7J and $\mathrm{K}$ ). The apical regions of the caryopsis sometimes were pink from mats of mycelium (Fig. 7J and $\mathrm{K}$ ).

Lesions in the floret stalk usually were visible only on cut surfaces after the stalks were excised from the floret (not shown) and usually were black. On the apical cut surface, they were crescent shaped and concentric to the stem axis. On the basal surface, a single lesion occupied all or most of the cut surface.

Occasionally, a narrow brown or black lesion (Fig. 7L) followed one or more vascular bundles on the exterior (abaxial) surface of the lemma. These lesions extended from the base to one-fourth to one-third the height of the lemma. Also, on the exterior lemma surface of some florets, dark brown lesions (not shown) occupied the two concave, semi-transparent regions beside the midvein (see location in Fig. 1E).

Red pigmented tissues sometimes were observed in uninfected florets from both inoculated and uninoculated plots. The red areas varied in shape from stripes (Fig. 7M) to spots (Fig. 7N). They were bright red, distinct from the dark reddish brown color of disease-associated lesions or from occasional pink masses of mycelium of $F$. graminearum.

Location of lesions. In the field experiment of 2001 in which florets were harvested in triplets, we obtained a total of 91 florets with one or more lesions (Table 2). Half of these florets were from the central floret of a triplet. The remaining half was divided equally between the two lateral florets. Thus, the central floret was twice as likely to have lesions as was each lateral floret.

The earliest lesions on the lemma and palea were found at 2 to 3 DAI, a day or two before lesions were first found on the caryopsis or stalk (Table 2). For all days of sampling in both 2001 and 2002, 134 florets had one or more lesions on the lemma and 135 on the palea, each approximately twice the number with lesions on the caryopsis or stalk and many more than on the awn (Table 2).

Many individual lesions on the lemma and palea were visible on both exterior (abaxial) and interior (adaxial) surfaces. In line with this, in 2001, the numbers of florets with lesions were similar on the two surfaces of the lemma (Fig. 8A) or palea (Fig. $8 C$ ). In 2002, however, more florets had lesions on exterior than interior surfaces (Fig. 8B and D). To investigate lesion visibility further, we selected a subset of lesions that were delineated well enough to determine whether they were coincident on both surfaces (i.e., whether lesions were similar in size, shape, and location on exterior and interior surfaces). In all, 81 coincident lesions were found on the lemma and 53 on the palea. On the other hand, 30 lesions were present on a given surface of the palea or lemma without a coincident lesion on the opposing surface. Most of these were located on exterior surfaces, most often on the apical half of the lemma or palea. These lesions averaged $1.2 \mathrm{~mm}$ in diameter (i.e., they apparently had not developed enough to be visible on the opposing surface).

Of the coincident lesions visible on both surfaces of the lemma, many matched lesions on the adjacent palea and on the caryopsis next to the palea. Together, these lesions formed a single locus of infection spreading through the lemma, palea, and caryopsis. In other florets, lesions in the palea matched lesions in the caryopsis but not lesions in the lemma. Conversely, lesions on the caryopsis nearly always matched lesions on the interior surface of the palea. Because we could not follow lesion spread over time in a given floret, we were unable to determine the progression of spread originating in the lemma, palea, or caryopsis.

We determined numbers of florets with lesions on the apical and basal halves of the lemma, palea, and caryopsis (Fig. 9) much as described earlier for florets with mycelial colonies. For the lemma and palea, more florets had lesions on the apical than on the basal half of both exterior and interior surfaces (Fig. 9A to D). The presence of more lesions on apical than basal halves in early stages of disease development is consistent with probable fungal invasion basipetally from the floret mouth. However, many florets had lesions on the basal half, indicating the lesions may have originated from fungal entry other than through the mouth. At $6 \mathrm{DAI}$ and later, numbers of florets with apical and basal lesions no longer differed consistently. However, lesions on the palea and lemma tended to be within $3 \mathrm{~mm}$ of either the apex or base of the floret regardless of the days after inoculation. For example, for 2001 and 2002 combined (excluding 12 DAI in 2001), lesions were within $3 \mathrm{~mm}$ of the apex of the lemma or palea in 62 florets and within $3 \mathrm{~mm}$ of the base in 37 florets. Relatively few lesions were in the floret midsection. On the caryopsis, differences between apical and basal halves were smaller and less consistent (Fig. 9E and F) than on the palea and lemma. As on the palea and lemma, lesions rarely were present in the midsection of the caryopsis.

Lesions in lodicules. The two lodicules located at the base of the caryopsis (Fig. 1F) were examined for lesions in the 105 florets dissected 4 to 6 DAI in 2002. None of the lodicules had lesions at 4 DAI, three florets had lesions in the two lodicules at 5 DAI, and three again at 6 DAI. Thus, visible lesions were present in lodicules in only $6 \%$ of florets examined. In five of the florets with these lodicules, lesions also were present in the base of the lemma, palea, or caryopsis. In all six florets, the apical cut surface of the excised floret stalk subtending the lodicules showed lesions. Thus, the few lodicules with lesions likely were associated with systemic spread of lesions in the stalk, lodicules, and basal portions of the lemma, palea, or caryopsis.

Lesions in stalks. Lesions were first seen in stalks in 2001 at 5 DAI, 2 to 3 days after they were first seen in the lemma and palea, and thereafter in increasing numbers of florets (Table 2). In 2002, stalk lesions were present at all sampling times, 4 to 6 DAI (Table 2). A total of 64 florets had lesions in the stalk for 2001 and 2002 combined. All these florets had lesions on the apical cut surface, and 24 also had lesions on the basal surface exposed when broken from the rachis node. None had lesions on the basal surface alone. This indicates that lesion spread was predominantly basipetal. In line with this, lesions in the stalks of 27 florets were associated with lesions in the basal half of the formerly attached lemma, palea, or caryopsis. In 17 other cases, the entire floret was chlorotic.

As described earlier, florets were harvested in triplets in the experiment of 2001. This was done to obtain information on spread of lesions between adjacent florets in the triplets. However, only four triplets were found with continuity in lesions between pairs of adjacent florets, one each at 5, 8, 10, and 12 DAI. In these cases, the cut faces of floret stalks largely were covered with one or more lesions. The participating florets of the triplet were covered partially or completely with lesions or were chlorotic.

TABLE 3. Colonization of anthers by Fusarium graminearum in unfixed samples of florets ${ }^{\mathrm{a}}$

\begin{tabular}{lccccc}
\hline & \multicolumn{5}{c}{ Number of florets } \\
\cline { 2 - 6 } DAI & \multicolumn{2}{c}{ Caught anthers $^{\mathrm{b}}$} & \multicolumn{2}{c}{ Exserted anthers } & Absent anthers $^{\mathrm{c}}$ \\
\cline { 2 - 6 } & Total & Colonized $^{\mathrm{d}}$ & Total & Colonized $^{\mathrm{d}}$ & Total \\
\hline 4 & 31 & 0 & 24 & 0 & 4 \\
5 & 26 & 2 & 30 & 3 & 3 \\
6 & 22 & 3 & 32 & 0 & 4 \\
8 & 16 & 4 & 37 & 2 & 7 \\
10 & 15 & 1 & 34 & 2 & 10 \\
12 & 7 & 1 & 34 & 0 & 16 \\
Total & 117 & 11 & 191 & 7 & 44 \\
\hline
\end{tabular}

a Samples as described in Table 2 for 4 to 12 days after inoculation (DAI) in 2001. Each day, 57 to 60 florets were examined.

b Two or three anthers of the floret were caught in the floret mouth.

c Anthers had fallen away from the floret.

d Two to three anthers were colonized. 
Although lesions spread from one floret to another through the rachis node, samples were too few in number to follow direction and timing of spread. Some lesions extended a few millimeters basipetally below the rachis node, where lesions were associated with vascular bundles (Fig. $7 \mathrm{O}$ and $\mathrm{P}$ ).

\section{DISCUSSION}

The experiments reported here were undertaken to learn how $F$. graminearum, under field conditions, gains entry into barley florets, bypassing the thick-walled epidermal cells that armor the exterior of the lemma and palea against direct penetration. The results indicate that the fungus gained access to the floret interior principally by two pathways: (i) through crevices between edges of the overlapping lemma and palea of the floret and (ii) through the apical floret mouth.

Hyphae developing from germinating macroconidia produced thin mycelial colonies closely appressed to exposed surfaces of the lemma, palea, and awn. The external surface of the lemma was only lightly colonized, as reported by others for wheat $(20$, 21,32). Colonies were more numerous near the base of the ventral furrow of the palea than elsewhere. This furrow faces the rachis,
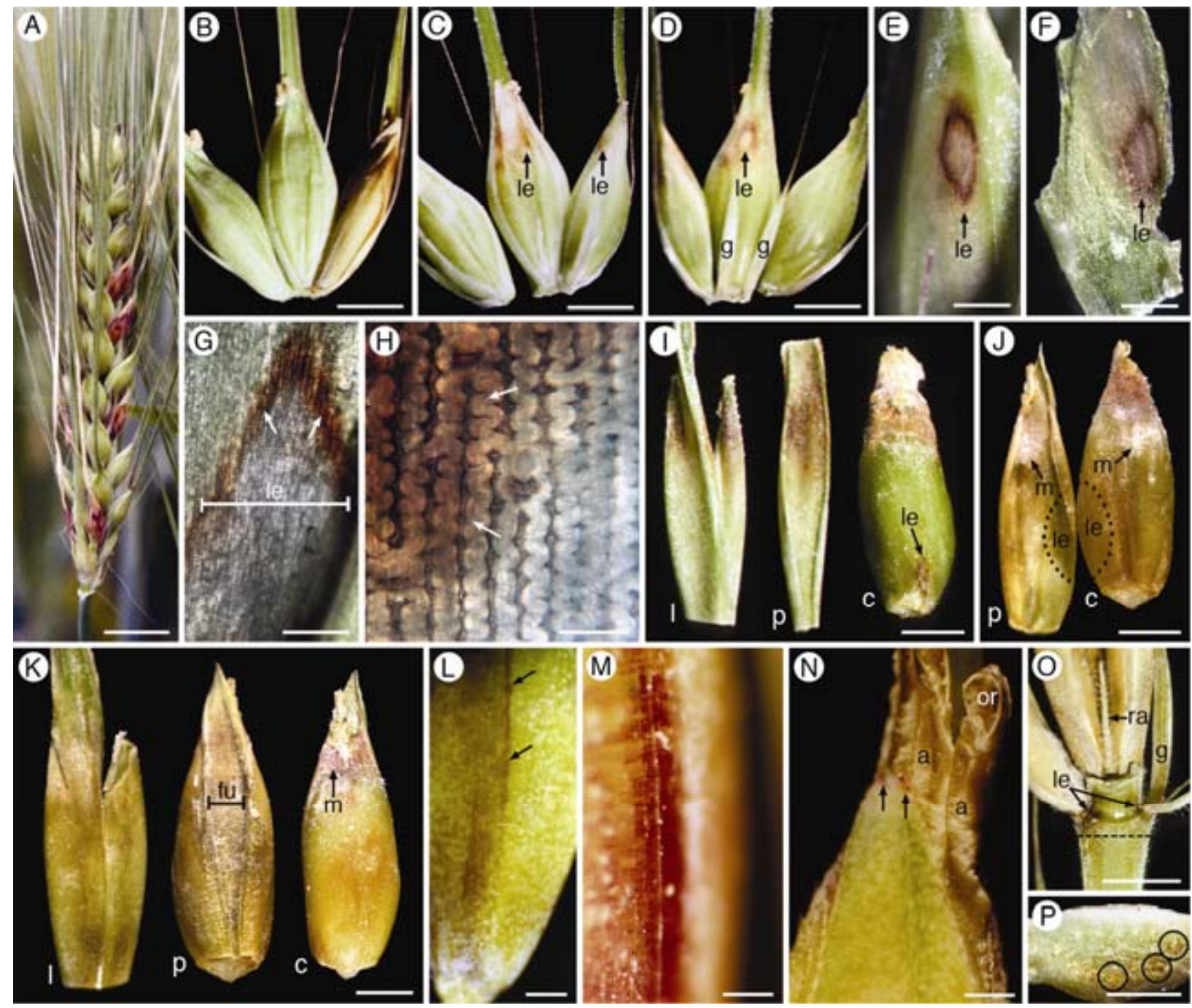

Fig. 7. Lesions in Robust barley florets after inoculation with Fusarium graminearum. All from field specimens except for $\mathbf{L}$ and $\mathbf{N}$. A, Florets entirely brown in barley head, 13 days after inoculation (DAI). Bar $=20 \mathrm{~mm}$. B, Aborted floret on right side of triplet, 8 DAI. Such florets, which occurred equally in inoculated and uninoculated plots, were more abundant in 2002 than 2001. Bar $=5 \mathrm{~mm}$. C and D, Lesions (le) on exterior (abaxial) surfaces near apex of a central floret (of a triplet), 6 DAI. C, Surface facing rachis, lesions on palea. Bar $=5 \mathrm{~mm}$. D, Surface facing away from rachis, lesion on lemma. Two glumes (g) subtend each floret; these rarely had visible lesions except for infections spreading from the rachis node as in $\mathbf{O}$. Bar $=5 \mathrm{~mm}$. $\mathbf{E}$ and $\mathbf{F}$, Lesion (le) visible on both exterior (abaxial) and interior (adaxial) surfaces of a lemma, 5 DAI. E, Exterior surface. Bar $=1.0 \mathrm{~mm}$. F, Interior surface. Note reddish-brown border to lesion. Bar $=1.0 \mathrm{~mm}$. G and $\mathbf{H}$, Close-up of reddish brown border (arrows) of a lesion (le) on exterior (abaxial) surface of lemma, 6 DAI. G, Medium magnification. Bar $=300 \mu$ m. $\mathbf{H}$, High magnification. Pigmented border tissue consists of intact thick-walled epidermal cells. Bar $=20 \mu \mathrm{m}$. I, Contiguous brown lesions in apical portions of lemma (1), palea (p), and caryopsis (c). White mycelium (with faint pink tint) is visible near apex of caryopsis. A small isolated lesion (le) is near the base of the caryopsis, 4 DAI. Bar $=3 \mathrm{~mm}$. J, Brown lesions (le) on interior (adaxial) surface of palea (p) were partially coincident with reddish brown lesions on surface of caryopsis (c). Masses of white mycelium (m) also were coincident, 4 DAI. Bar $=3 \mathrm{~mm}$. K, Lemma (l), palea (p), and caryopsis (c) of floret showing brown discoloration on nearly all surfaces. White mycelium present in furrow (fu) of palea; a mass of pink mycelium $(\mathrm{m})$ at apex of caryopsis, 4 DAI. Bar $=3$ mm. $\mathbf{L}$, Browning (arrow) associated with a vein located on exterior (abaxial) surface of lemma, 4 days after stalk of detached floret was inoculated with $F$. graminearum in a growth chamber experiment. Composite of two photographs. Bar $=1 \mathrm{~mm}$. M, Red pigment at edge of lemma in an uninfected floret; this occurred occasionally in the field in both inoculated and uninoculated plots, 12 DAI. Bar $=300 \mu \mathrm{m}$. N, Small spots of red pigment (arrows) at apex of uninfected florets in a growth chamber experiment. Dehisced, partially exserted anthers (a) are present, one with apical orifice (or) containing a few remaining pollen grains. Bar $=$ $1 \mathrm{~mm}$. O, Brownish black lesions (le) in rachis node at the base of a floret triplet, 10 DAI. Right floret and apical portion of rachis were removed. Discolored base of a glume (g) is in view. Lesion at base of central floret is partially hidden by stub left after rachis was removed. Exposed rachilla (ra) was in the pocket between the furrow of the palea and base of the rachis. Dashed line shows location of rachis cross section in $\mathbf{P}$. Bar $=3 \mathrm{~mm}$. $\mathbf{P}$, Cross section of rachis cut at dashed line as shown in $\mathbf{O}$. Brown vascular bundles (encircled) are visible. Bar $=1 \mathrm{~mm}$. 
forming a sheltered pocket likely to be favorable for maintenance of moisture between periods of irrigation applied in the morning and evening. The mycelial network often grew out of the furrow and spread laterally over the exposed surface of the palea to the edge of the lemma which overlaps the palea. The fungus also reached the crevice from mycelial colonies on the exterior of the lemma, although these were fewer in number than on the palea.

The fungus entered the crevice between the lemma and palea, usually by continuing to grow on the palea surface within the crevice. Once through the crevice, it presumably was protected from desiccation and exposure to sunlight and had direct access to the interior surfaces of the lemma, palea, and caryopsis, all of which have thin-walled epidermal cells susceptible to fungal penetration. The crevice between lemma and palea remained open for fungal entry until $\approx 8 \mathrm{DAI}$, when the lemma and palea fused.

In addition to entry through the lemma-palea crevice, the fungus entered florets through the apical mouth. Mycelial colonies on the adaxial surface of the awn grew basipetally, forming a continuous mycelial network extending through the floret mouth onto the interior surface of the lemma. This brought the fungus into contact with the caryopsis, where it is not covered by the palea, as well as with interior surfaces of the palea. Of 315 colonized florets, 60 had colonized awns, more than the number of florets colonized on interior surfaces of the lemma, 37, or palea, 14. In line with basipetal colonization of the floret interior, the interior lemma surface and all caryopsis surfaces were colonized in more florets on apical than basal halves at 1 to 6 DAI.

On rare occasions, the fungus reached the floret mouth by growing to the apex of the floret over the exterior surface of the lemma. This route was indicated also in investigations by SEM for $F$. culmorum and $F$. avenaceum on wheat by Kang and coworkers $(9,12)$. Each pathogen produced only sparse mycelium on the exterior lemma surface and did not penetrate the lemma epidermis. However, hyphae sometimes grew over the apical edge of the lemma, apparently onto the interior lemma surface within the floret cavity. Similar fungal growth was observed on the glume that subtends the wheat spikelet. Kang and co-workers did not assess the importance of this pathway for floret infection. Our observations of barley florets indicate that the pathway from the exterior of the lemma over the apex to the interior is less important than the pathway leading from the adaxial awn surface to the lemma surface in the interior of the floret. However, considering both routes combined, the fungus probably entered by way of the floret mouth more often than through the lemma-palea crevice. This was indicated by the greater number of florets with mycelial colonies on apical than basal halves on the interior surfaces of the lemma and palea. However, some of the colonies on the apical halves may have originated from hyphae entering laterally through the crevice instead of the floret mouth.

In two florets, shoulders of the developing caryopsis pushed open the floret mouth, exposing the apical brush apex of the caryopsis to fungal attack at 3 to 4 DAI. Such exposed caryopses would be subject to direct infection in the field. Skadsen and Hohn (24) found that the brush apex of the caryopsis was exposed directly to inoculum in cv. Morex when inoculated at the milk to dough stage of kernel development. Exposed caryopses are not desirable in mature barley kernels, especially in malting barley. Certainly, barley lines with exposed caryopses should be avoided in breeding for Fusarium head blight resistance.

Anthers caught in the floret mouth in our field experiments provided a bridge favorable for fungal entry into some florets, as indicated previously by Pugh et al. (20). Abundant mycelium developed on these anthers. However, the number of florets with colonized anthers was small in our experiments. Of 117 florets with caught anthers, only 11 were colonized with mycelium. Likewise, only seven florets had colonized, fully exserted anthers present on the exterior floret surface. These numbers are low compared with the number of florets with lesions, 84 , in the same data set, and also low compared with numbers with mycelial colonies in a separate set sampled for mycelium. We conclude that anther colonization had only a minor role in invasion through the floret mouth in our field experiments with barley.
2001

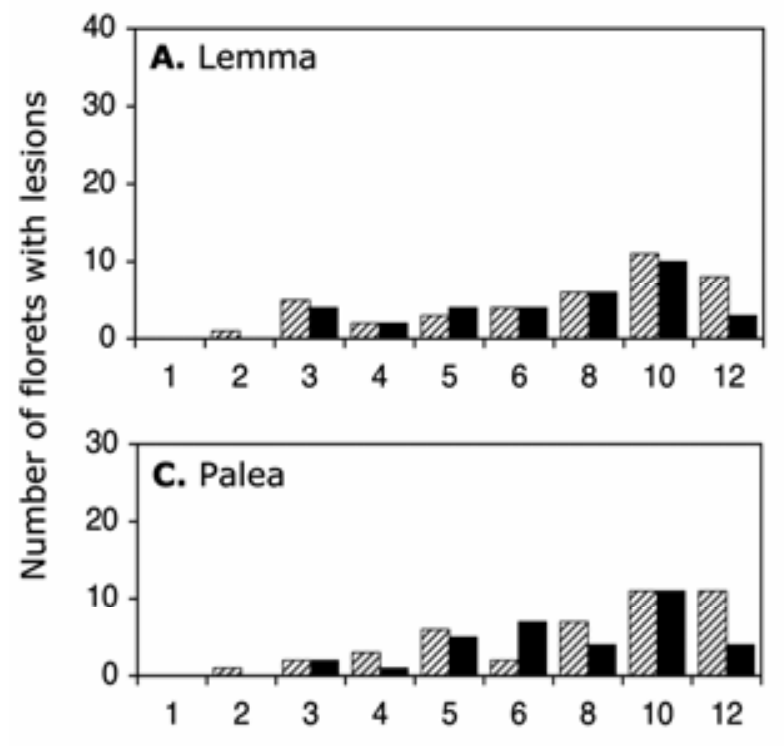

2002
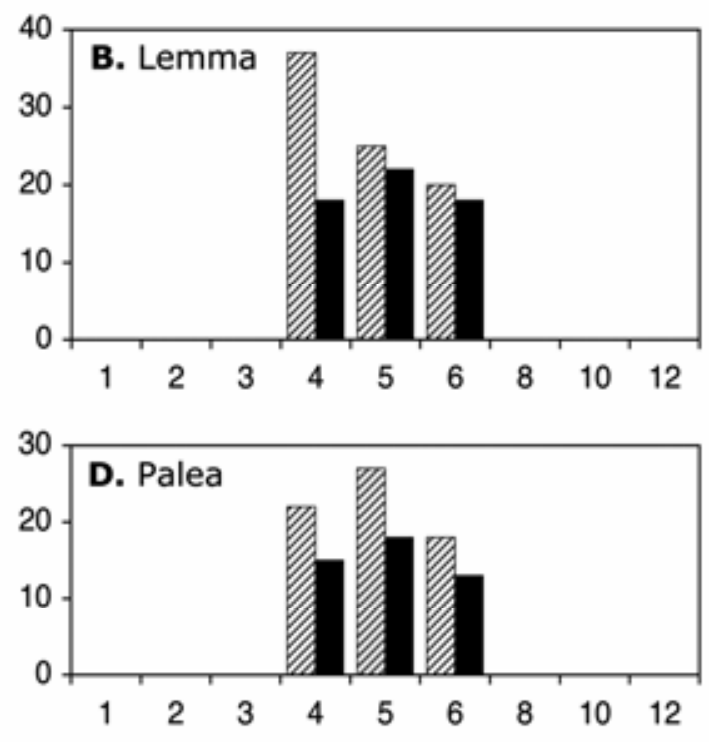

Days after inoculation

Exterior (abaxial) surface $\mathbb{Z I I I}$

Interior (adaxial) surface

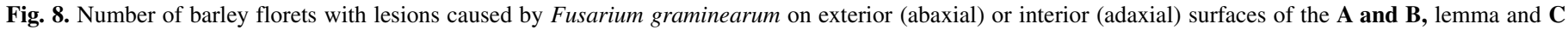

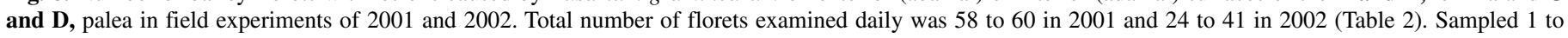
12 days in 2001; 4 to 6 days in 2002. Some florets had lesions on both exterior and interior surfaces. 
The anther may be less important in barley than in wheat for floret infection. Barley anthers are exserted after dehiscence of pollen so that caught or fully exserted anthers no longer contain large numbers of pollen grains. In wheat, dehiscence occurs after anthers are exserted, when they have a full complement of pollen. This pollen probably adds to the nutrients available for the head blight fungus invading wheat. Chemical substances in wheat anthers promote growth of $F$. graminearum on artificial media, although their role in floret infection is uncertain $(6,28,29)$. Although infection levels have been higher in the presence of anthers in some experiments (17), disease incidence was unchanged by removal of anthers before spray inoculation (23).

In examining colonized floret surfaces microscopically, we did not see evidence of hyphal entry into stomates. Mycelial networks often spread over the stomates that are present in rows bordering each vein of the lemma and palea. This happened often for stomates associated with veins that border the ventral furrow of the palea where mycelial networks were abundant. Hyphae crossed or came near stomates but never were seen to enter them. This was true not only for barley florets in heads inoculated in the field, but also for detached barley florets inoculated and incubated in the laboratory (13). On the other hand, instances of apparent stomatal entry have been described in wheat for $F$. graminearum on glumes using light microscopy (19) and for F. culmorum on floret interior surfaces by SEM (9). However, Kang et al. (11) did not find stomatal entry in wheat by Microdochium nivale, another head blight pathogen. Indirect evidence for stomatal entry in wheat florets was provided by Pritsch et al. (19), who found that thin-walled parenchyma located beneath stomates was invaded by F. graminearum, probably from hyphae entering stomates. We did not investigate whether substomatal parenchyma is present in
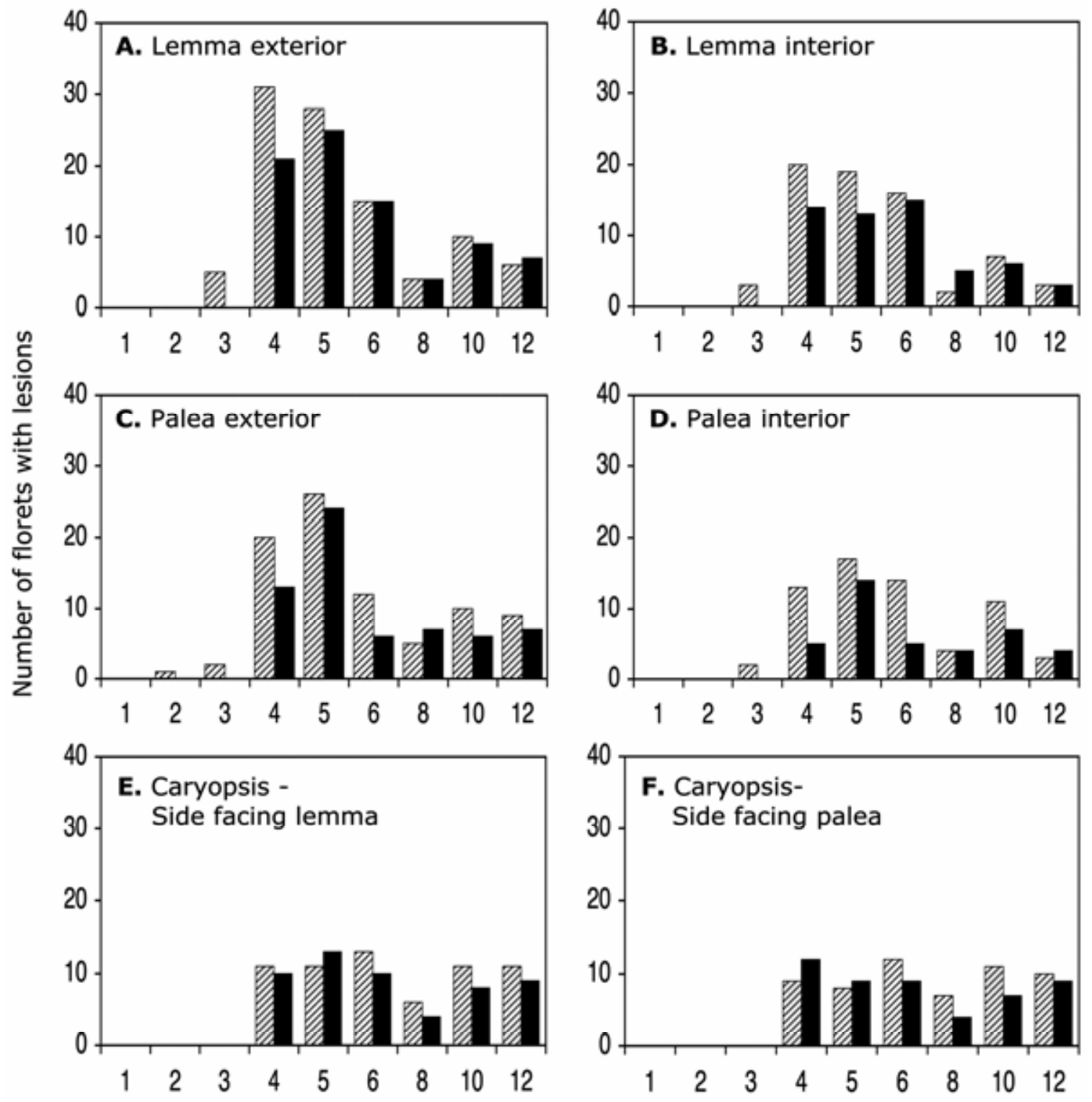

Days after inoculation

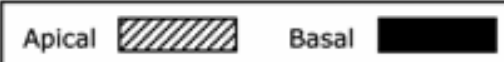

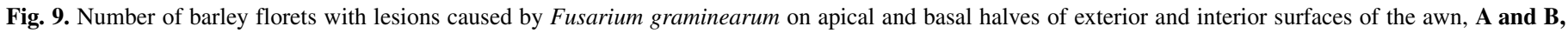

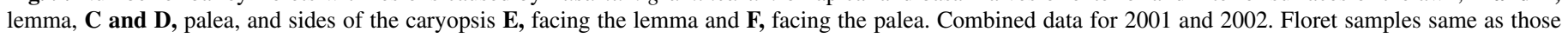
described in Figure 8. Some florets had lesions on both apical and basal surfaces. 
barley florets. Nevertheless, our results indicate that stomatal penetration by $F$. graminearum in barley is a rare event.

Several characteristics of the principal fungal colonies observed on floret surfaces support the assumption that they were $F$. graminearum. Some hyphae clearly originated from macroconidial inoculum. These were similar to hyphae that subsequently were present on surfaces of the lemma and palea. Although hyphae on the surface of the caryopsis differed by being less frequently branched than on the lemma and palea, similar hyphae were produced on the caryopsis of florets inoculated and incubated in the laboratory. Most definitive, however, was the presence of macroconidia on floret surfaces at 6 DAI in 2000. These spores were present singly or in groups of two to three on floret surfaces only in regions colonized by the fungus. Although detached from hyphae in our fixed specimens, these spores appeared to be freshly produced in contrast to macroconidia from inoculum, which usually collapsed earlier and rarely were seen by 6 DAI. The putative $F$. graminearum mycelium was distinct from the principal contaminating fungus, an Alternaria sp., which was present in increasing amounts 8 to $12 \mathrm{DAI}$.

The lactophenol blue fixing and staining procedure used to detect mycelium on surfaces of floret parts did not reveal fungal hyphae within floret tissues and probably did not show fungal development beneath the cuticle of the lemma, palea, or caryopsis. Subcuticular growth of $F$. graminearum was shown to occur in the glumes that subtend wheat spikelets (19) and also in barley leaves (3). The role of subcuticular mycelium in infection of barley florets needs investigation. However, any subcuticular growth on exterior surfaces of the lemma and palea is unlikely to spread through the thick-walled epidermal and hypodermal cells into the floret interior.

Although mycelial colonies on exterior surfaces of florets consisted of a sparse network of hyphae, the extent of fungal growth probably exhausted reserves of carbon compounds and other nutrients in germinating macroconidia. Kang and Buchenauer (9) described hyphal tracks visible by SEM on wheat floret surfaces, which suggested that the fungus can digest and utilize components of waxy cuticle. We have observed similar tracks on the barley palea surface by SEM (D. E. Krueger and W. R. Bushnell, unpublished data). Partial digestion of floret surfaces probably enables the fungus to spread over them to the lemma-palea crevice or the floret mouth for entry into the floret.

In contrast to our experiments using macroconidia to inoculate barley, ascospores from crop residues serve as the principal source of head blight infection in barley and wheat fields. For sprayinoculated barley grown in a growth chamber, macroconidia and ascospores gave similar disease severities (27). The two spore types also gave similar results when they were injected directly into wheat florets (25). Still, fungus development from macroconidia and ascospores needs to be compared histologically in inoculated florets, especially with respect to pathways of entry into the floret.

As lesions became visible 4 DAI and later, their location corroborated postulated pathways of fungal entry into florets and provided insight into pathogenesis within the floret. Although the lesions were not examined histologically, floret tissues of wheat are known to be penetrated and colonized by $F$. graminearum $(16,20,31,32)$ as well as by three other head blight pathogens: F. culmorum, F. avenaceum, and Microdochium nivale $(9,11,12)$. In our samples, some lesions were circular to oval, suggesting they each had spread outward from a single center of infection. Others were amorphous in shape, possibly a consequence of multiple infections from mycelial colonization within the floret. Some lesions were uniformly reddish brown to dark brown; others had reddish brown borders surrounding light green centers or, in a few cases, white centers. Similar lesions with bleached centers surrounded by brown borders in response to F. graminearum were described on outer glumes of wheat florets by
Bennett (1) and show in a photograph by B. Steffensen of barley florets in a review by Bushnell et al. (3). Phenolic substances induced by the head blight fungus (14) probably contribute to reddish brown and brown pigmentation of lesions. The white centers are of interest because green barley leaf tissues turned white if incubated in light after treatment with deoxynivalenol (DON) (4). In a few instances, tissues bordering white centers turned reddish brown in DON-treated leaves (T. E. Seeland and W. R. Bushnell, unpublished data). We conclude that DON likely has a role as an inducer of symptoms in tissues infected by $F$. graminearum. Whether tissues within lesions were white, green, yellow, or brown, they apparently did not collapse until 8 to 12 DAI. Thick-walled cells in the exterior epidermis probably delayed collapse in the lemma and palea.

Lesions were found in nearly equal numbers of florets in the lemma and palea. The lesions developed at two principal locations: (i) within $3 \mathrm{~mm}$ of the floret apex, in line with growth of mycelial colonies on floret surfaces through the floret mouth as discussed earlier; and (ii) within $3 \mathrm{~mm}$ of the floret base, probably a result of fungal entry through the lemma-palea crevice or, in a small number of florets, through the rachis from adjacent infected florets into the floret stalk. Somewhat more lesions were located in apical than basal halves of the lemma and palea at 3 to $6 \mathrm{DAI}$, attesting to the importance of the floret mouth as a pathway of fungal entry.

Lesions spread readily between lemma and palea, as shown by the presence of matching lesions in both. However, the direction of spread could not be discerned. In some cases of matching lesions, the lemma and palea possibly were invaded simultaneously from mycelium growing in the region of overlap between them. This would require that the mycelium at the interface overcome the resistance of the thick-walled epidermis of the palea abaxial surface.

In the caryopsis, lesions developed 1 or 2 days later and were fewer in number than in the lemma and palea. The lesions in the caryopsis always were associated with lesions in the palea. This suggests that penetration and spread of the fungus within tissues of some florets occurred simultaneously in the palea and caryopsis from mycelium located at the interface between them. Surfaces at the palea-caryopsis interface apparently are well suited for mycelial spread. Alternatively, the lesions in the palea may have originated at the lemma-palea interface and then spread through the palea to its interface with the caryopsis. This is less likely because the thick-walled external (abaxial) epidermis of the palea would offer some protection to invasion from the lemma, as noted above.

Although most individual lesions were visible on both sides of the lemma or palea, some small lesions ( 2 to $3 \mathrm{~mm}$ in diameter) were visible on only one surface, most often on the exterior surface of the lemma. Whether these were young lesions or older lesions with restricted growth was not determined. These lesions contributed to the larger numbers of florets with lesions on exterior surfaces than on interior surfaces of the lemma and palea in 2002.

In our field plots, overhead mist irrigation in morning and evening was sufficient to allow spore germination and mycelial spread over exterior surfaces of the lemma and palea, enabling the fungus to reach the lemma-palea crevice or the floret mouth for access to the floret interior. Free water was not maintained on floret surfaces on most DAI, but the daily moisture regime was adequate for floret infection. Moisture levels in the pocket sheltered by the rachis at the base of the palea furrow probably were higher than elsewhere, favoring abundant mycelial colonization.

In support of conclusions reached here from field investigations for principal pathways of floret entry, Lewandowski (13) documented similar pathways in laboratory experiments. Florets were detached from plants grown in growth chambers and 
placed on water agar in petri dishes. The florets were spot inoculated with mycelium growing on small mung bean agar blocks or spray inoculated with macroconidial suspensions. In both cases, mycelium grew over the exterior lemma surface to the floret mouth or the lemma-palea crevice, reaching the floret interior and colonizing the caryopsis by 48 to $72 \mathrm{~h}$ after inoculation. The mycelium on the exterior floret surface was more abundant in the moist environment of the dishes than it was in the field, but entered the floret by the same principal pathways.

In barley cultivars with reduced susceptibility, disease incidence is reduced as measured by reduction in number of florets or heads that exhibit lesions (27). This is similar to a type of resistance described in wheat by Schroeder and Christensen (22), which often is designated type 1 . In barley, there is little or no spread of infection from one rachis node to another in the head in contrast to wheat in which the fungus spreads from node to node. Resistance to such spread is designated type 2 (27). In a pioneering investigation, Kang and Buchenauer (10) followed development of $F$. culmorum by transmission electron microscopy in two wheat cultivars (Frontana and Arina) with type 2 resistance, showing induction of wall appositions in host cells and reduced spread from floret to rachis. To understand reduced incidence in barley, fungus development and host response need to be investigated at all stages of head blight development, but must include initial colonization of floret surfaces, entry into the floret interior, and invasion of tissues therein.

\section{APPENDIX}

Glossary of terms for components of the barley floret and associated structures. Definitions are based on Briggs (2), Metcalfe (15), and our observation of barley.

Bract-General term for leaf-like structures, including the lemma, palea, and the two glumes that subtend the floret.

Brush apex-Caryopsis apex, which is covered with remnants of two brushy stigmas as the caryopsis enlarges.

Caryopsis - Structure developed from fertilized ovary. The caryopsis contains an embryo and endosperm. Combined with the surrounding palea and lemma, the caryopsis forms the mature barley kernel.

Floret-Flower-like structure which is produced near the base of a rachilla. In ascending order of attachment, it consists of a lemma, a palea, two lodicules, three stamens, and an ovary with two feathery stigmas.

Glume-One of two small bracts subtending each floret.

Lemma-Abaxial bract (with respect to the rachis) that overlaps the edges of the palea. Together with the palea, the lemma encloses the floral cavity.

Lodicule-One of two small brush-like structures located within the floral cavity between the base of the palea and the base of the caryopsis. The lodicule is postulated to have a role in temporary floret opening when anthers emerge.

Palea-Adaxial (with respect to the rachis) bract that, together with the lemma, encloses the floral cavity. Edges of the palea are overlapped by edges of the lemma.

Rachilla-Structure that arises from a rachis node and bears two glumes and a floret. It extends apically beyond the level of floret attachment to form a short, sterile, brush-like projection partially surrounded by the palea. In wheat, the rachilla serves as the axis of a spikelet in which two glumes and three or more florets usually are produced.

Rachis - Central axis to which florets are attached in the head (the inflorescence).

Rachis node-Site of floret attachment. Three florets are attached to each node in six-rowed barley.

Stalk-Base of the rachilla, including points of attachment of the lemma and palea.

\section{ACKNOWLEDGMENTS}

Mention of a trademark or proprietary product does not constitute a guarantee or warranty of the product by the U.S. Department of Agriculture or the University of Minnesota and does not imply its approval to the exclusion of other products that also may be suitable. Any opinions, findings, conclusions, or recommendations expressed in this publication are those of the authors and do not necessarily reflect the view of the U.S. Department of Agriculture or the University of Minnesota. This material is based in part on the M.S. thesis of S. M. Lewandowski, and upon work supported by the Agricultural Research Service, U.S. Department of Agriculture in a cooperative project with the U.S. Wheat \& Barley Scab Initiative. The authors thank R. Dill-Macky for advice and use of field plots and for reviewing the manuscript; J. Morrison for preparation of figures; A. Bushnell for word processing; B. Hazen, K. Leonard, and C. Pritsch for reviewing the manuscript; and T. Seeland for technical assistance.

\section{LITERATURE CITED}

1. Bennett, F. T. 1931. Gibberella saubinetii (Mont.) Sacc. on British cereals. Ann. Appl. Biol. 18:158-177.

2. Briggs, D. E. 1978. Barley. Chapman and Hall, London.

3. Bushnell, W. R., Hazen, B. E., and Pritsch, C. 2003. Histology and physiology of Fusarium head blight. Pages 44-83 in: Fusarium Head Blight of Wheat and Barley. K. J. Leonard and W. R. Bushnell, eds. The American Phytopathological Society, St. Paul, MN.

4. Bushnell, W. R., Seeland, T. M., Perkins-Veazie, P., Krueger, D. E., Collins, J., and Russo, V. M. 2005. The effects of deoxynivalenol on barley leaf tissues. Pages 270-284 in: Genomic and Genetic Analysis of Plant Parasitism and Defense. S. Tsuyumu, J. E. Leach, T. Shiraishi, and T. Wolpert, eds. The American Phytopathological Society, St. Paul, MN.

5. Dill-Macky, R. 2003. Inoculation methods and evaluation of Fusarium head blight resistance in wheat. Pages 184-210 in: Fusarium Head Blight of Wheat and Barley. K. J. Leonard and W. R. Bushnell, eds. The American Phytopathological Society, St. Paul, MN.

6. Engle, J. S., Lipps, P. E., Graham, T. L., and Boehm, M. J. 2004. Effects of choline, betaine, and wheat floral extracts on growth of Fusarium graminearum. Plant Dis. 88:175-180.

7. Kang, Z., and Buchenauer, H. 1999. Immunocytochemical localization of Fusarium toxins in infected wheat spikes by Fusarium culmorum. Physiol. Mol. Plant Pathol. 55:275-288.

8. Kang, Z., and Buchenauer, H. 2000. Ultrastructural and cytochemical studies on cellulose, xylan and pectin degradation in wheat spikes infected by Fusarium culmorum. J. Phytopathol. 148:263-275.

9. Kang, Z., and Buchenauer, H. 2000. Cytology and ultrastructure of the infection of wheat spikes by Fusarium culmorum. Mycol. Res. 104:10831093.

10. Kang, Z., and Buchenauer, H. 2000. Ultrastructural and immunocytochemical investigation of pathogen development and host responses in resistant and susceptible wheat spikes infected by Fusarium culmorum. Physiol. Mol. Plant Pathol. 57:255-268.

11. Kang, Z., Huang, L., and Buchenauer, H. 2004. Ultrastructural and cytochemical studies on infection of wheat spikes by Microdochium nivale. Z. Pflanzenkrankh. Pflanzenschutz 111:351-361.

12. Kang, Z., Zingen-Sell, I., and Buchenauer, H. 2005. Infection of wheat spikes by Fusarium avenaceum and alterations of cell wall components in the infected tissue. Eur. J. Plant Pathol. 111:19-28.

13. Lewandowski, S. M. 2005. Pathway of infection of Fusarium graminearum in 6-row susceptible barley. M.S. thesis, University of Minnesota, St. Paul.

14. McKeehen, J. D., Busch, R. H., and Fulcher, R. G. 1999. Evaluation of wheat (Triticum aestivum L.) phenolic acids during grain development and their contribution to Fusarium resistance. J. Agric. Food Chem. 47:1476-1482.

15. Metcalfe, C. R. 1960. General morphology of the grass plant. Pages xvxxxvi in: Anatomy of the Monocotyledons. I. Gramineae. Clarendon Press, Oxford.

16. Miller, S. S., Chabot, D. M. P., Ouellet, T., Harris, L. J., and Fedak, G. 2004. Use of a Fusarium graminearum strain transformed with green fluorescent protein to study infection in wheat (Triticum aestivum). Can. J. Plant Pathol. 26:453-463.

17. Parry, D. W., Jenkinson, P., and McLeod, L. 1995. Fusarium ear blight (scab) in small grain cereals. A review. Plant Pathol. 44:207-238.

18. Prat, H. 1932. L'epiderme des Graminées. Ann. Sci. Nat. Bot. 10th Ser. Vol. 14.

19. Pritsch, C., Muehlbauer, G. J., Bushnell, W. R., Somers, D. A., and Vance, C. P. 2000. Fungal development and induction of defense response genes 
during early infection of wheat spikes by Fusarium graminearum. Mol. Plant-Microbe Interact. 13:159-169.

20. Pugh, G. W., Johann, H., and Dickson, J. G. 1933. Factors affecting infection of wheat heads by Gibberella saubinetii. J. Agric. Res. 46:771-797.

21. Ribichich, K. F., Lopez, S. E., and Vegetti, A. C. 2000. Histopathological spikelet changes produced by Fusarium graminearum in susceptible and resistant wheat cultivars. Plant Dis. 84:794-802.

22. Schroeder, H. W., and Christensen, J. J. 1963. Factors affecting the resistance of wheat to scab caused by Gibberella zeae. Phytopathology 53:831-838.

23. Shaner, G. 2003. Epidemiology of Fusarium head blight of small grain cereals in North America. Pages 84-119 in: Fusarium Head Blight of Wheat and Barley. K. J. Leonard and W. R. Bushnell, eds. The American Phytopathological Society, St. Paul, MN.

24. Skadsen, R. W., and Hohn, T. M. 2004. Use of Fusarium graminearum transformed with $g f p$ to follow infection patterns in barley and Arabidopsis. Physiol. Mol. Plant Pathol. 64:45-53.

25. Stack, R. W. 1989. A comparison of the inoculum potential of ascospores and conidia of Gibberella zeae. Can. J. Plant Pathol. 11:137-142.

26. Stack, R. W. 2003. History of Fusarium head blight with emphasis on North America. Pages 1-34 in: Fusarium Head Blight of Wheat and Barley. K. J. Leonard and W. R. Bushnell, eds. The American Phyto- pathological Society, St. Paul, MN.

27. Steffenson, B. J. 2003. Fusarium head blight of barley: Impact, epidemics, management, and strategies for identifying and utilizing genetic resistance. Pages 241-295 in: Fusarium Head Blight of Wheat and Barley. K. J. Leonard and W. R. Bushnell, eds. The American Phytopathological Society, St. Paul, MN.

28. Strange, R. N., Deramo, A., and Smith, H. 1978. Virulence enhancement of Fusarium graminearum by choline and betaine and of Botrytis cinerea by other constituents of wheat germ. Trans. Br. Mycol. Soc. 70:201-207.

29. Strange, R. N., and Smith, H. 1971. A fungal growth stimulant in anthers which predisposes wheat to attack by Fusarium graminearum. Physiol. Plant Pathol. 1:141-150.

30. Tu, C. 1930. Physiologic specialization in Fusarium spp. causing headblight of small grains. Minnesota Agric. Exp. Stn. Tech. Bull. 74.

31. Tu, D. S. 1950. Factors affecting the reaction of wheat varieties to head blight infection caused by Gibberella zeae. Ph.D. diss., Ohio State University, Columbus.

32. Wanyoike, M. W., Kang, Z., and Buchenauer, H. 2002. Importance of cell wall-degrading enzymes produced by Fusarium graminearum during infection of wheat heads. Eur. J. Plant Pathol. 108:803-810.

33. Zadoks, J. C., Chang, T. T., and Konzak, C. F. 1974. A decimal code for the growth stages of cereals. Weed Res. 14:415-421. 